\title{
Starphenes and Phenes: Structures and Properties
}

\author{
Elias C. Rüdiger ${ }^{\mathbf{a}}$ \\ Matthias Müller ${ }^{a}$ \\ Jan Freudenberg*a,b \\ Uwe H. F. Bunz ${ }^{* a, c}$ (D) \\ ${ }^{a}$ Organisch-Chemisches Institut, Ruprecht-Karls-Universität Heidelberg, Im \\ Neuenheimer Feld 270, 69120 Heidelberg, FRG \\ uwe.bunz@oci.uni-heidelberg.de \\ freudenberg@oci.uni-heidelberg.de \\ ${ }^{\mathrm{b}}$ InnovationLab, Speyerer Straße 4, 69115 Heidelberg, Germany \\ 'Centre for Advanced Materials, Ruprecht-Karls-Universität Heidelberg, Im \\ Neuenheimer Feld 225, 69120 Heidelberg, FRG
}

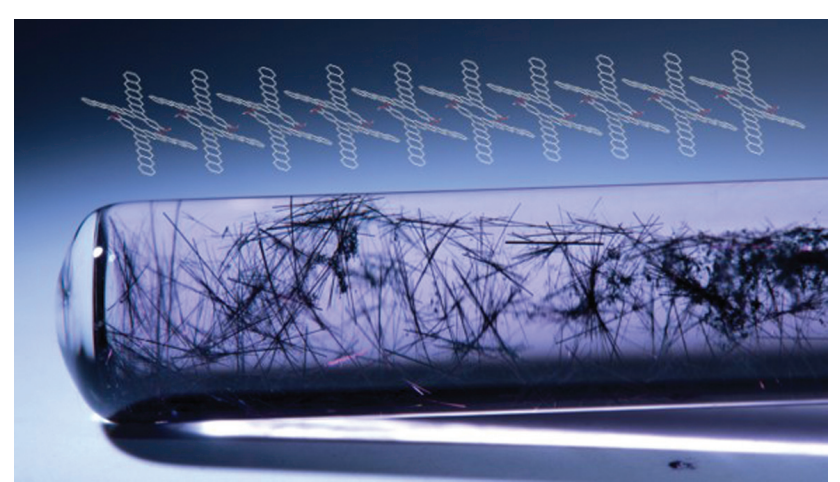

An interesting class of materials is represented by the acenes ${ }^{11 a}$; pentacene, the largest easy-to-handle representative of this class was first prepared in the 1930s by Clar, using different chemical approaches. ${ }^{11 \mathrm{~b}, \mathrm{c}}$ Pentacene can be sublimed and is therefore fairly easy to use-even for physicists. As it is not highly soluble, several precursor routes have been developed to facilitate solution-based handling. In the solid state, pentacene (1) packs in a herringbone motif (Figure 2) and is a potent p-channel semiconductor, useful for thin-film transistors and other electronic devices. ${ }^{12-14}$

Pentacene's lack of solubility and stability was perceived as a drawback, until Anthony et al. introduced TIPS-ethynyl substituents to the acene core via alkynylation and subsequent deoxygenation of pentacenequinone. ${ }^{15-17}$ The as-formed product TIPS-Pen (6) is soluble, displays enhanced stability, and has been employed in a range of different applications, such as organic thin-film transistors, ${ }^{18,19}$ sensing, ${ }^{20,21}$ and prominently singlet fission. ${ }^{22,23}$

Using this strategy, Anthony could also stabilize hexacenes and heptacenes, although more bulky silanes, e.g. $\mathrm{Si}(\text { cyclopentyl })_{3}{ }^{24}$ or $\mathrm{Si}(\mathrm{TMS})_{3},{ }^{25}$ were necessary. This concept is not only applicable to the acenes as it has also been applied to $N$-heteroacenes by $\mathrm{us}^{26-29}$ and others, ${ }^{30-32}$ exploiting additional steric or electronic stabilization. Other strategies to stabilize acenes involve on-surface chemistry, ${ }^{33,34}$ kinetic stabilization in thin films, ${ }^{35}$ and isolation of acenes in matrices. ${ }^{35,36}$

One fairly under-developed aspect was the synthesis and characterization of the so-called "phenes" (Figure 3), ${ }^{37-39}$ i.e. aromatic hydrocarbons with $n$ annulated rings that display two identical ( $n$ : odd-numbered) or differing by one in length ( $n$ : even-numbered) acene arms that are connected through a single benzene ring. The number of overall catenated benzene rings determines the name of the phene. ${ }^{37,40}$ Then, benzophenanthrene would be tetraphene, and Figure 3 displays the structures of pentaphene (7), hexaphene (8), and undecaphene $(\mathbf{9})$. If the branching ring is not positioned as centrally 
as possible, digits are added to denote the number of annulated rings in each direction [cf. heptaphene-(2,4) (10) vs. heptaphene (11)].

One of the reasons for the absence of larger phenes was their lack of solubility, combined with the lack of good synthetic access. Green fluorescent heptaphene (11) was synthesized by Clar in the early 1930s-but without solubility-mediating groups the synthesis and purification of larger congeners is futile, although several theoretical publications ${ }^{41}$ have investigated their electronic structures. Here we

\section{Biographical Sketches}

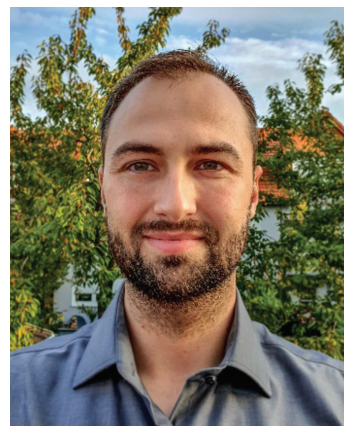

Elias Rüdiger was born in Heidelberg, Germany. Since making contact with the chemistry and physical properties of starphenes in his master thesis, he focused on synthesis and analysis of semiconducting materials. The following years he specialized in unusual stabilization concepts for large acenes and their functionality in organic electronics. Finally, Elias received his Dr. rer. nat. (2018) for organic chemistry in the group of Prof. Uwe Bunz at the Ruprecht-KarlsUniversität in Heidelberg.

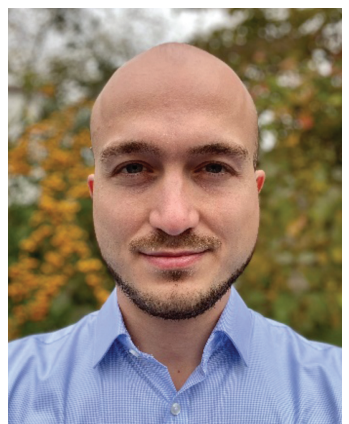

During his master thesis in the group of Prof. Frank Würthner, Matthias Müller focused on supramolecular chemistry for organic electronics. After obtaining his M.Sc. degree in chemistry from the University of Würzburg in 2016 , he moved to Heidelberg, joining the group of Prof. Bunz. He finished his PhD (summa cum laude) in organic chemistry recently, investigating unusual stabilization methods for large, acene-type scaffolds.

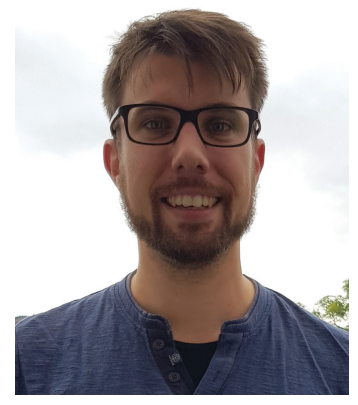

Jan Freudenberg received his Master of Science and Dr. rer. nat. (2016, summa cum laude) from the Ruprecht-KarlsUniversität Heidelberg. Within his master thesis he developed water-soluble luminophors for sensing applications, before moving into the field of aggregation-induced emitters as well as host materials for blue (Ph)OLEDs. Currently, he is a group leader of Prof. Bunz' acene and heteroacene subgroup. Since 2016, he is also a group leader at InnovationLab, Heidelberg, under the supervision of Prof. Klaus Müllen. Jan's research interests include printed organic electronics, interphase modification in devices and development of organic materials derived from (aza)acenes.

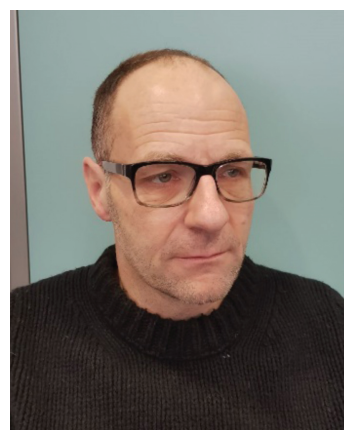

Uwe H. F. Bunz, born in Neheim-Hüsten, Germany received his Dipl. Chem. and Dr. rer. nat. (1990, summa cum laude) from the LMU Munich. After a postdoctoral stay in Berkeley he worked at MPIP Mainz, with Klaus Müllen, where he was awarded his venia legend in 1997. Professorial position at the University of South Carolina and at Georgia Institute of Technology followed, before he moved to Heidelberg. He is Chaired Professor at the Organisch-Chemische Institut der Ruprecht-Karls-Universität Heidelberg since 2010 and also a founding Director of the Centre of Advanced Materials at the University of Heidelberg. His scientific interests involve conjugated (water-soluble) polymers for sensoric applications such as chemical tongues and noses as well as $\mathrm{N}$-heteroacenes and $\mathrm{N}$-heteroarene chemistry. 
<smiles>c1ccc2cc3cc4cc5ccccc5cc4cc3cc2c1</smiles>

Pentacene 1

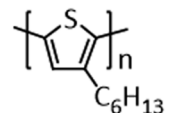

P3HT<smiles>[R]C1([R])c2cc(C)ccc2-c2ccc(CC)cc21</smiles>

Polyfluorene<smiles>[R]N1C(=O)c2cc(-c3ccc(-c4cc(CCCC)cs4)s3)c3c4c(cc(C)c(c24)C1=O)C(=O)N([R])C3=O</smiles>

N2200

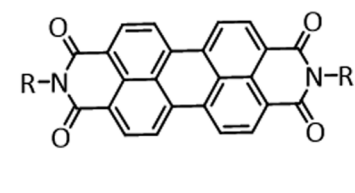

Perylene bisimide

5

Figure 1 Examples of different molecular and polymeric organic p- and n-type semiconductors.

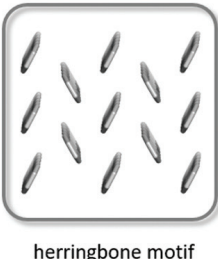

herringbone motif

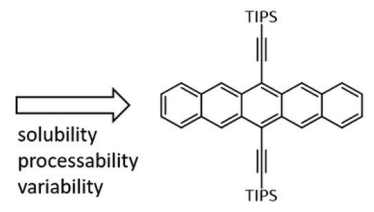

TIPS-Pen

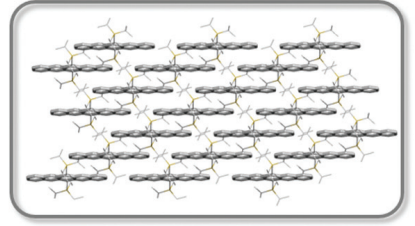

brickwall motif

Figure 2 Stabilization of pentacene using TIPS-ethynyl substituents by Anthony et al. ${ }^{15,66}$

describe our adventures in the synthesis of benzophenes, starphenes, and other related aromatics including acenes carrying triphenylenes and heterotriphenylenes units.

\section{Starphenes}

In starphenes a single benzene ring is surrounded by three identical arene substituents; the polycyclic (aza)

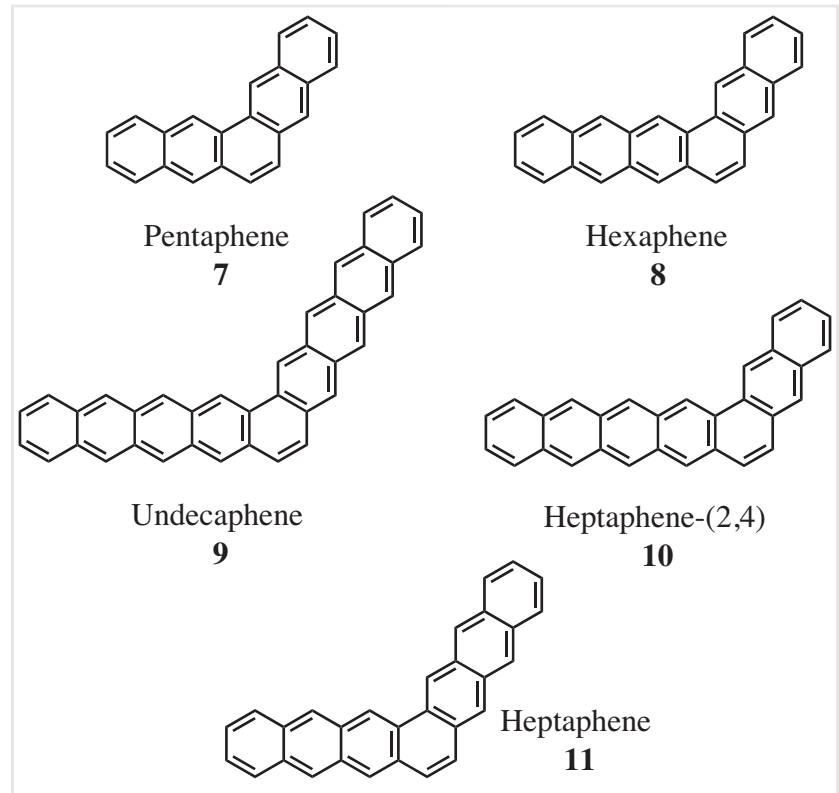

Figure 3 Examples of different phenes. hydrocarbon displays $D_{3 h}$ symmetry. While triphenylene [tetrastarphene-(1,1,1), 12 $]^{42,43}$ and hexaazatrinaphthylene (HATNA, 13) ${ }^{44-46}$ as well as their derivatives ${ }^{47}$ are known and investigated (cf. Figure 4), their larger hydrocarbon congeners are almost unknown. To prove that a complete aromatic conjugation does not exist in starphenes, decastarphene-(3,3,3), the largest unsubstituted derivative, was synthesized by Clar and Mullen in $1968 .{ }^{40}$

Lynett and Maly reported a four-step synthesis for trinaphthylenes by palladium-catalyzed aryne trimerization $^{48}$; the same strategy was later utilized by Peña et al. to obtain star-shaped nanographenes. ${ }^{49,50}$ We simplified and modularized the access to trinaphthylenes 16. A simple Yamamoto coupling of dibromonaphthalenes 13a-f gave cyclotrimers 16a-f in one step in reasonable to good yields (Scheme 1). ${ }^{51}$

The solid-state packing of these trinaphthylenes is highly dependent on the size of the alkoxy substituents. In the case of methoxylated 16a, layers with a distance of

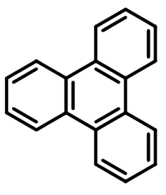

12<smiles>c1ccc2nc3c(nc2c1)c1nc2ccccc2nc1c1nc2ccccc2nc31</smiles>

13
Figure 4 Structures of triphenylene 12 (left) and HATNA 13 (right). 


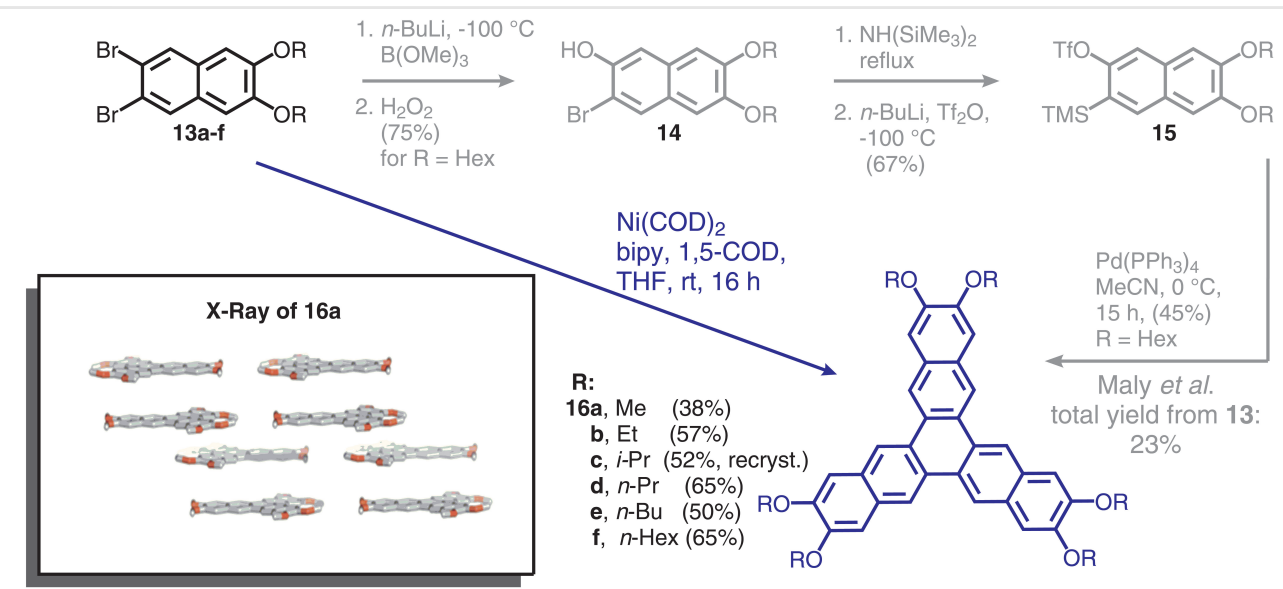

Scheme 1 Synthesis of substituted heptastarphen-(2,2,2) 17a-f using a simple Yamamoto-type cyclotrimerization. (Adapted with permission from Rüdiger et al. ${ }^{51}$ Copyright 2016 American Chemical Society.)

$3.5 \AA$ are formed, in which all molecules have the same orientation, whereas in adjacent planes the molecules are rotated by $180^{\circ}$ (Scheme 1 ).

When using dibromotetracene $\mathbf{2 3}$, we conveniently extended this methodology and isolated the larger star- phene with tetracene-based arms in yields exceeding 50\%. This simple cyclotrimerization was also used when a substituted dibromopentacene was employed to give a starphene consisting of three pentacene units (Scheme 2). The dibromides $\mathbf{2 3}$ and $\mathbf{2 4}$ were prepared according to
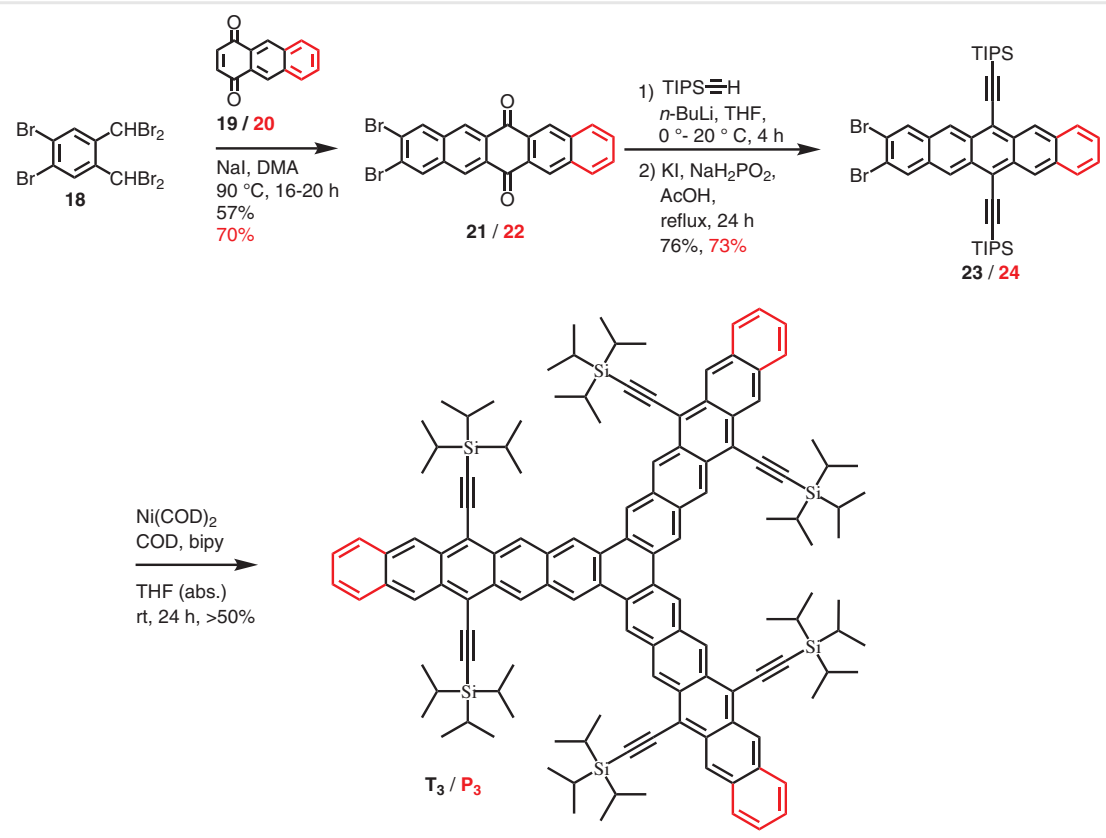

Scheme 2 Synthesis of $\mathrm{Br}_{2}$ TIPS-Tet 23 and $\mathrm{Br}_{2}$ TIPS-Pen 24, and the Yamamoto-type cyclotrimerization to form the starphenes $\mathbf{T}_{\mathbf{3}}$ and $\mathbf{P}_{\mathbf{3}} .{ }^{52}$ 

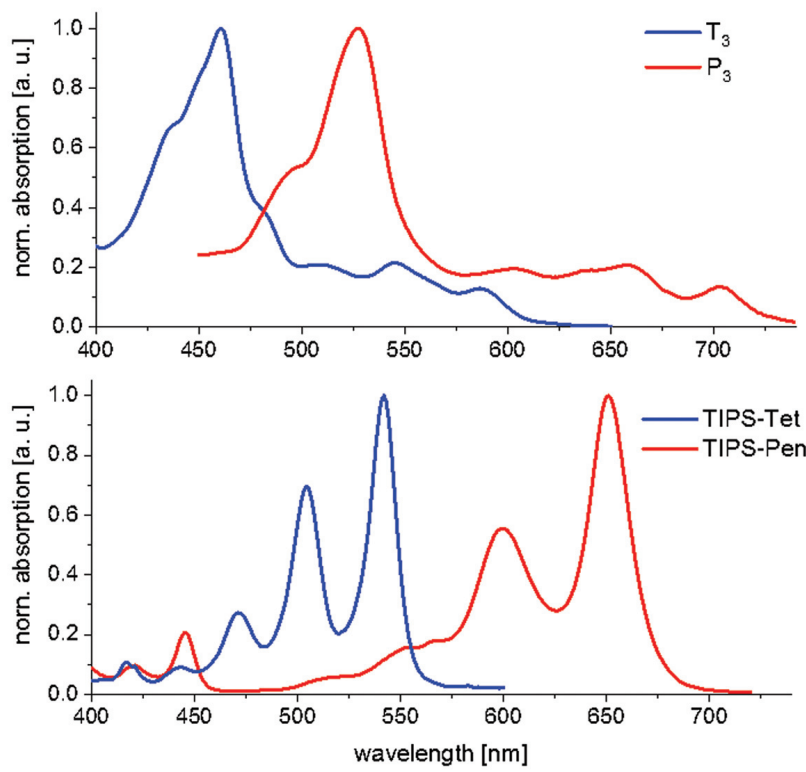

Figure 5 Top: normalized absorption spectra of starphene $\mathbf{T}_{\mathbf{3}}\left(\lambda_{\max , \text { abs }}=\right.$ $586 \mathrm{~nm})$ and $\mathbf{P}_{\mathbf{3}}\left(\lambda_{\text {max,abs }}=703 \mathrm{~nm}\right)$ in dichloromethane. Bottom: low-energy absorption bands of TIPS-tetracene and TIPS-pentacene for comparison. ${ }^{52}$
Scheme 2. Starting from the tetrabromide 18, the Cava reaction with $19 / 20$ yields the quinones $21 / 22$, which are alkynylated and deoxygenated into $\mathbf{2 3 / 2 4}$ in good overall yields of 43 and $51 \%$ for this three-step synthesis. ${ }^{52}$

Figure 5 depicts the UV-vis spectra of the two starphenes $\left(\mathbf{T}_{\mathbf{3}}\right.$ and $\mathbf{P}_{\mathbf{3}}$ ). Both show the expected redshift-as in a formal sense all three units are either pentacenes or hexacenes, but ones which share the ring in the middle. Therefore, the redshift is not large when compared to TIPS-Pen $\left(\lambda_{\text {max }, \text { abs }}=\right.$ $643 \mathrm{~nm})^{53}$ or TIPS-Tet $\left(\lambda_{\text {max,abs }}=534 \mathrm{~nm}\right) .{ }^{54}$ We conclude that there is some electronic interaction of the acene arms with each other, but it is not large, similar to triphenylenes, although oscillator strengths are much higher as suggested by the more intense absorption at lower energies. We obtained single-crystal structures of both starphenes and found in both cases a slight twist of one of the bis(TIPSethynyl)-equipped arms (Figure 6). There is some electronic overlap of the arms with adjacent molecules, but the materials cannot form perfect stacks in which the centers are on top of each other, due to the bulky silyl substituents. The twist in the solid state implies deviation from the symmetric propeller-shaped DFT-structure prediction in vacuum.

Although the Yamamoto reaction is expedient for cyclotrimerization, it has its limits. First, the position of the TIPSethynyl substituents is crucial for its outcome. Attempts to position them more towards the center of the starphenes

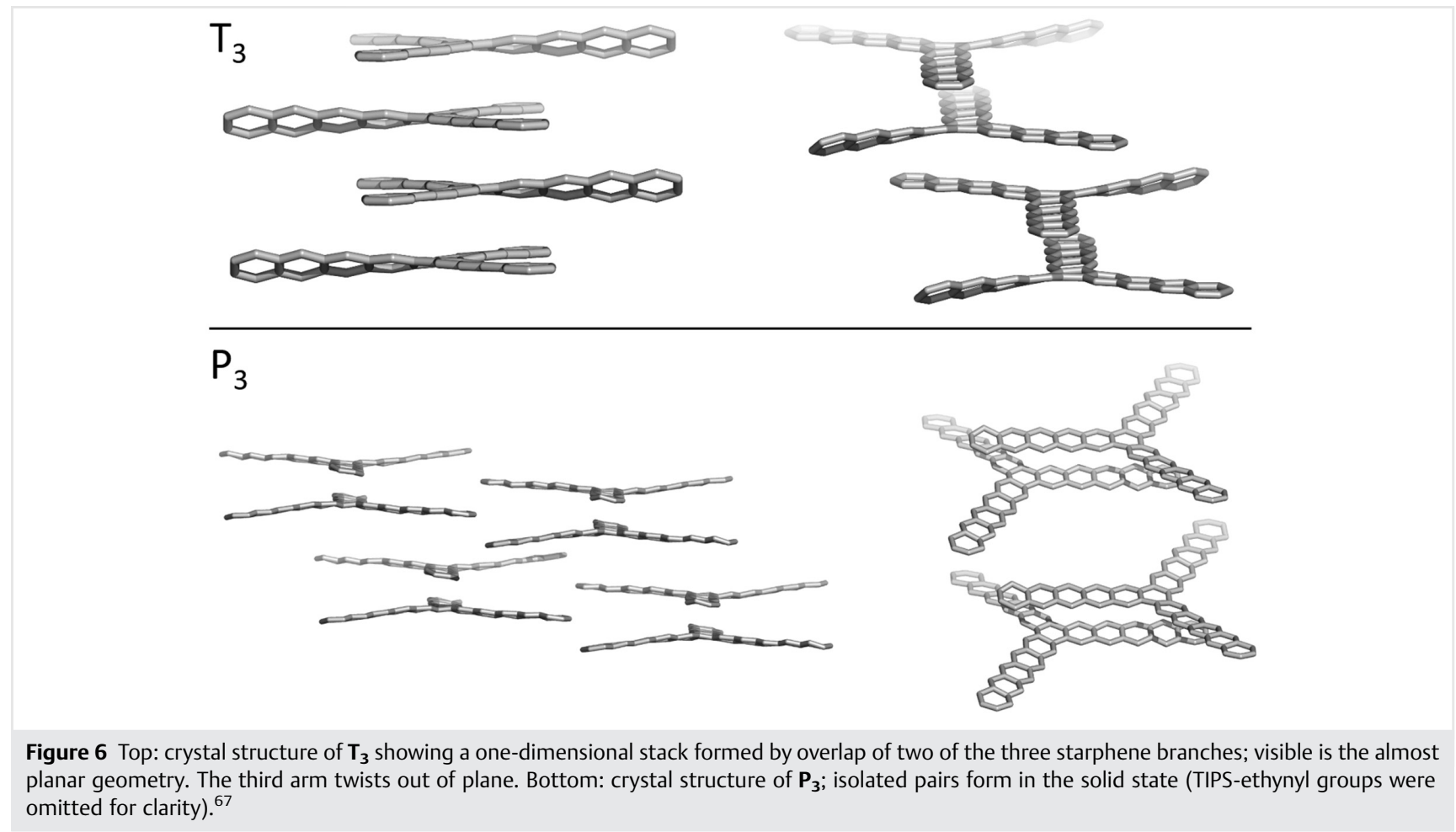

Organic Materials 2019, 1, 1-18 
using a 9,10-bis(TIPS-ethynylated) dibromoanthracene ${ }^{28}$ were not successful under our standard coupling conditions, probably due to the repulsion of the bulky TIPS substituents between different acene arms. Second, the Yamamoto cyclotrimerization is limited to hydrocarbon systems-coupling of dibromophenazines or even larger bishalogenated azaacenes resulted mostly in decomposition and/or dehalogenation. These systems are, however, easily accessible via condensation reactions as recently demonstrated by Mateo-Alonso et al., synthesizing giant, star-shaped N-doped nanographenes. ${ }^{55}$

\section{Phenes, Bisbenzannulated and COT-Based Acenes}

The success of the Yamamoto coupling opened the possibility to perform shotgun-type syntheses in which a second dibromoarene is used as a feed to access not only bisbenzannulated phenes but also other molecular architectures in which the acene is embedded in a 3D scaffold, such as tetrabenzocyclooctatetraenes. As a by-product of our starphene synthesis, we observed traces of tetramers, inseparable from higher linear oligomers, although formation of the cyclotrimers was greatly favored. Yamamoto reported the formation of tetrathienylenes in his seminal publication in 1991, hinting that formation of eightmembered rings is possible. ${ }^{56}$ An overview of our exploratory project is given in Figure 7 -the different synthetic and materials science extensions including optoelectronic characterization with subsequent targeted synthesis are highlighted. After choosing a suitable building block to embed into new constructs of higher geometry, the properties of these structural motives were screened. The most promising were studied in the solid state through the construction of organic field-effect transistors. Finally, a selective synthesis to access the best performing materials had be developed.

Scheme 3 shows the statistical synthesis of different coupling products, and our nomenclature is explained in Figure 8.

When one equivalent of dibromides 23/24 is mixed with 2.5 equivalents of either 1,2-dibromobenzene (25) or 3,4dimethoxy-1,2-dibromobenzene (26), cylooligomers are obtained under Yamamoto conditions. For the hydrocarbons, separation by simple column chromatography was not possible. Preparative recycling gel-permeation chromatography cleanly separated a number of different compounds otherwise difficult to access (Figure 9). ${ }^{57}$

Some features should be noted: we find not only trimeric benzophenes such as $\mathbf{T}_{\mathbf{2}} \mathbf{B}$ and $\mathbf{T B}_{\mathbf{2}}$ or $\mathbf{P}_{\mathbf{2}} \mathbf{B}$ and $\mathbf{P B}_{\mathbf{2}}$, but also cyclotetramers such as $\mathbf{T B}_{\mathbf{3}}$ and $\mathbf{P B}_{\mathbf{3}}$ or $\mathbf{T}_{\mathbf{2}} \mathbf{V}_{\mathbf{2}}$ and PVPV. Although we use an excess of the benzene or veratrole derivative, the $\mathbf{T}_{\mathbf{2}^{-}}$and $\mathbf{P}_{\mathbf{2}}$-products are more abundant than

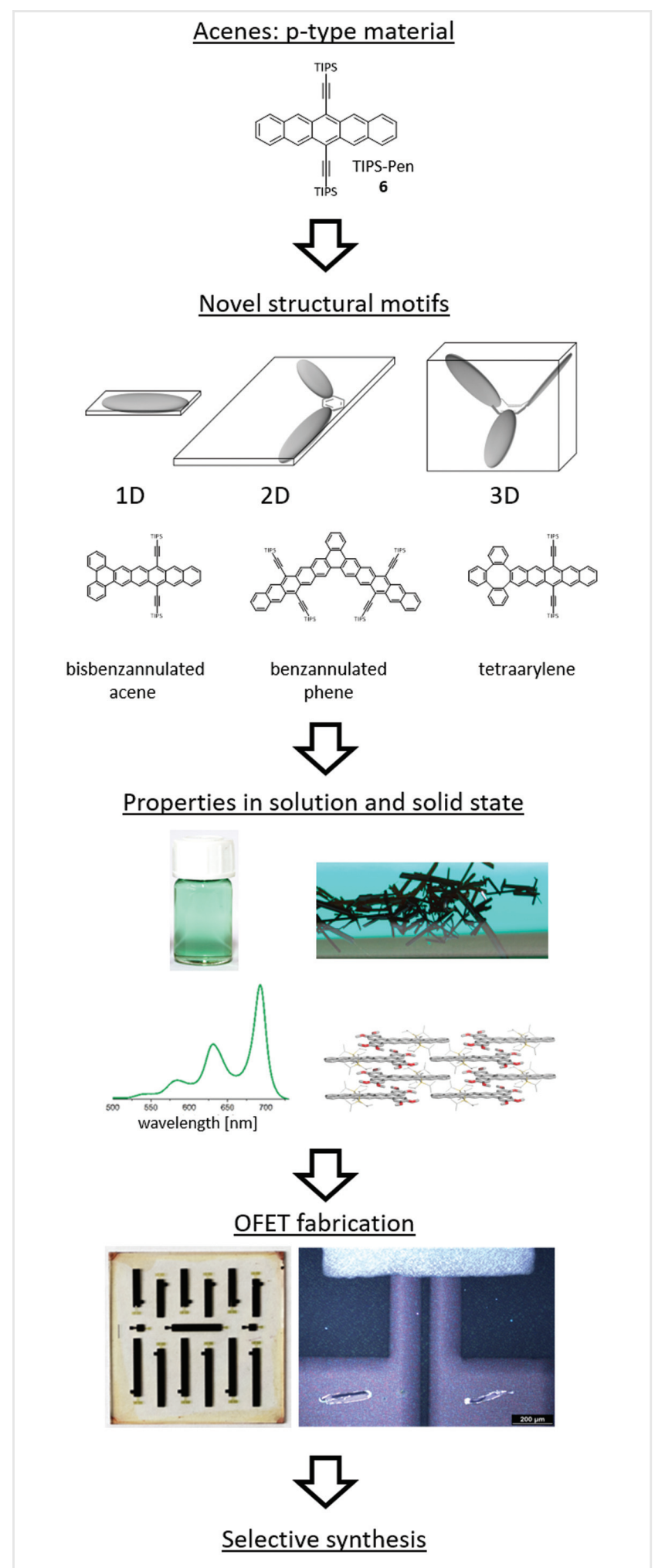

Figure 7 Screening process to access novel acene-based phenes and COTs. (Parts of Figure 7 adapted with permission from Rüdiger et al. ${ }^{63}$ Copyright 2018 John Wiley and Sons.) 


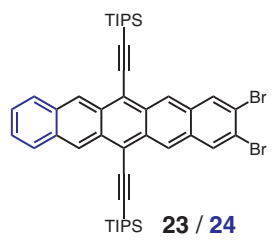

1.0 eq.

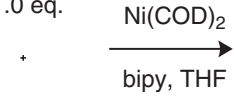

$\mathrm{C}_{\mathrm{Br}}^{\mathrm{Br}}$

RT, $16 \mathrm{~h}$

25, $\mathrm{R}=\mathrm{H}$

26, $\mathrm{R}=\mathrm{OMe}$

2.5 eq.

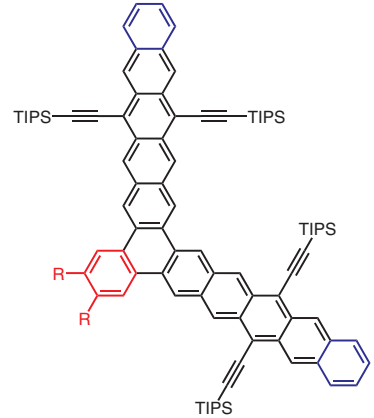

Tetracene: $\mathbf{T}_{2} \mathbf{B}, \mathrm{R}=\mathrm{H}, 28 \%$

$\mathrm{T}_{\mathbf{2}} \mathrm{V}, \mathrm{R}=\mathrm{OMe}, 40 \%$

Pentacene: $\mathbf{P}_{\mathbf{2}} \mathbf{B}, \mathrm{R}=\mathrm{H}, 18 \%$

$\mathrm{P}_{\mathbf{2}} \mathbf{V}, \mathrm{R}=\mathrm{OMe}, 41 \%$

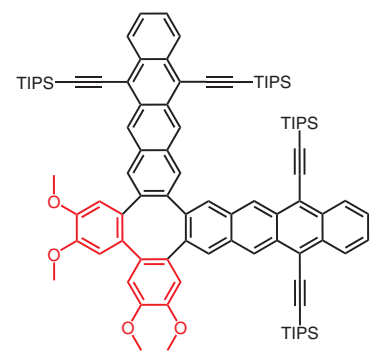

Tetracene: $\mathbf{T}_{\mathbf{2}} \mathbf{V}_{\mathbf{2}}, \mathbf{2 0} \%$

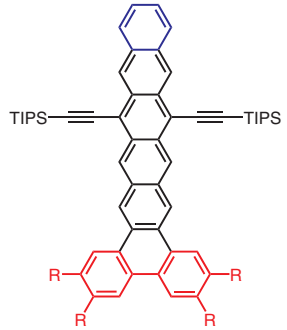

$\mathrm{TB}_{2}, \mathrm{R}=\mathrm{H}, 16 \%$

$\mathrm{TV}_{2}, \mathrm{R}=\mathrm{OMe}, 10 \%$

$\mathbf{P B}_{2}, \mathrm{R}=\mathrm{H}, 10 \%$

$\mathrm{PV}_{2}, \mathrm{R}=\mathrm{OMe}, 11 \%$

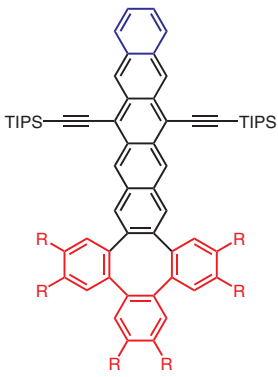

$\mathrm{TB}_{3}, \quad \mathrm{R}=\mathrm{H}, 10 \%$

$\mathrm{TV}_{\mathbf{3}}, \mathrm{R}=\mathrm{OMe}$, traces

$\mathrm{PB}_{3}, \mathrm{R}=\mathrm{H}, 8 \%$

$\mathrm{PV}_{3}, \mathrm{R}=\mathrm{OMe}$, traces

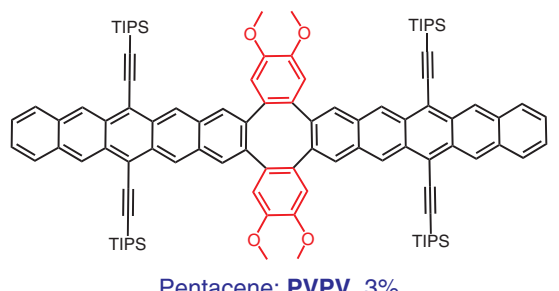

Scheme 3 Synthesis of different phene types via Yamamoto coupling. ${ }^{57}$

their bisbenzannulated counterparts $\mathbf{T} \mathbf{X}_{\mathbf{2}}$ and $\mathbf{P} \mathbf{X}_{\mathbf{2}}$. This must be due to the differential reactivity of the bromides. Dibromoveratrole, the most electron-rich dibromide in this series, reacts slower than dibromobenzene $\mathbf{2 5}$, and therefore gives the highest amount of the $\mathbf{T}_{\mathbf{2}^{-}}$and $\mathbf{P}_{\mathbf{2}^{-}}$-cyclotrimers.
A new feature of this reaction is the isolation of trisbenzocyclooctatetraene derivatives $\mathbf{T B}_{\mathbf{3}}$, species that are virtually unknown.

In the case of veratrole $\mathbf{2 6}$, two cyclooctatetraene-type products, $\mathbf{T}_{\mathbf{2}} \mathbf{V}_{\mathbf{2}}$ and PVPV, are formed in 20 and $3 \%$ yield,

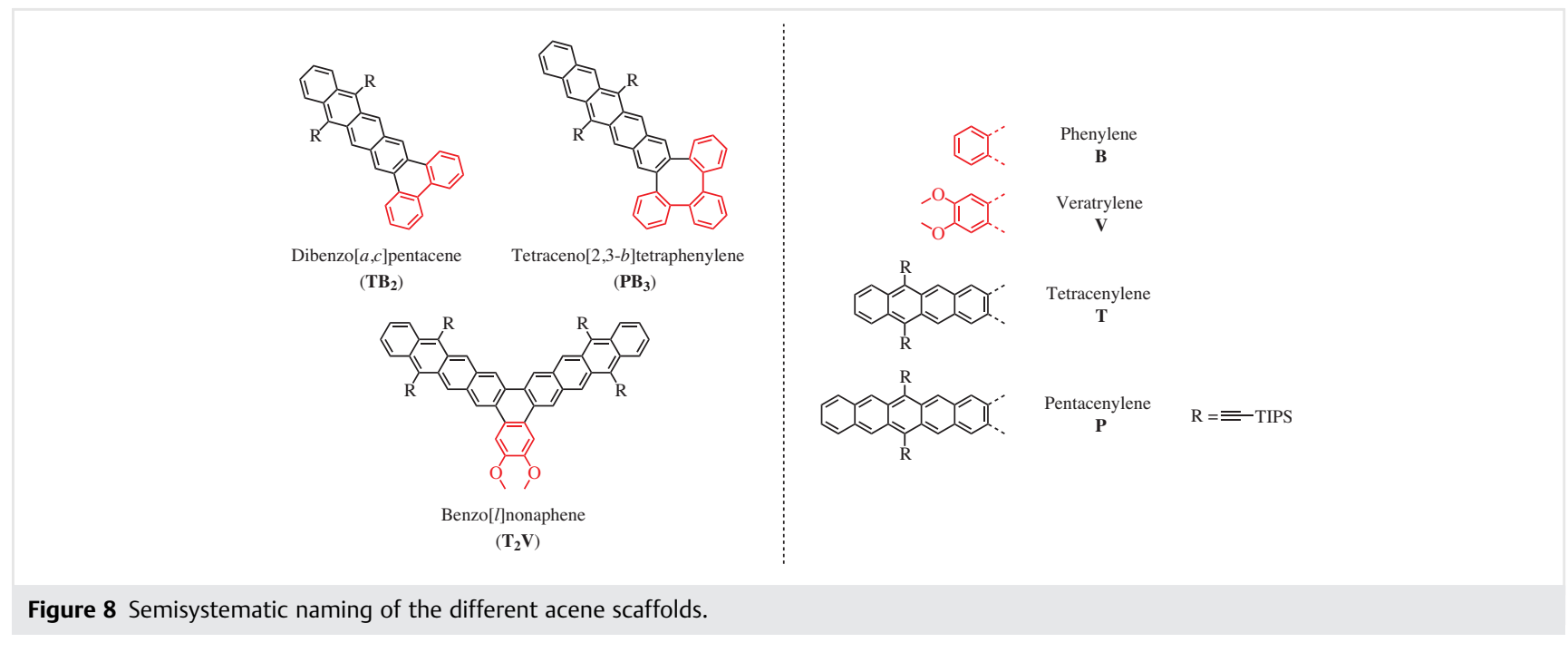

Organic Materials 2019, 1, 1-18 

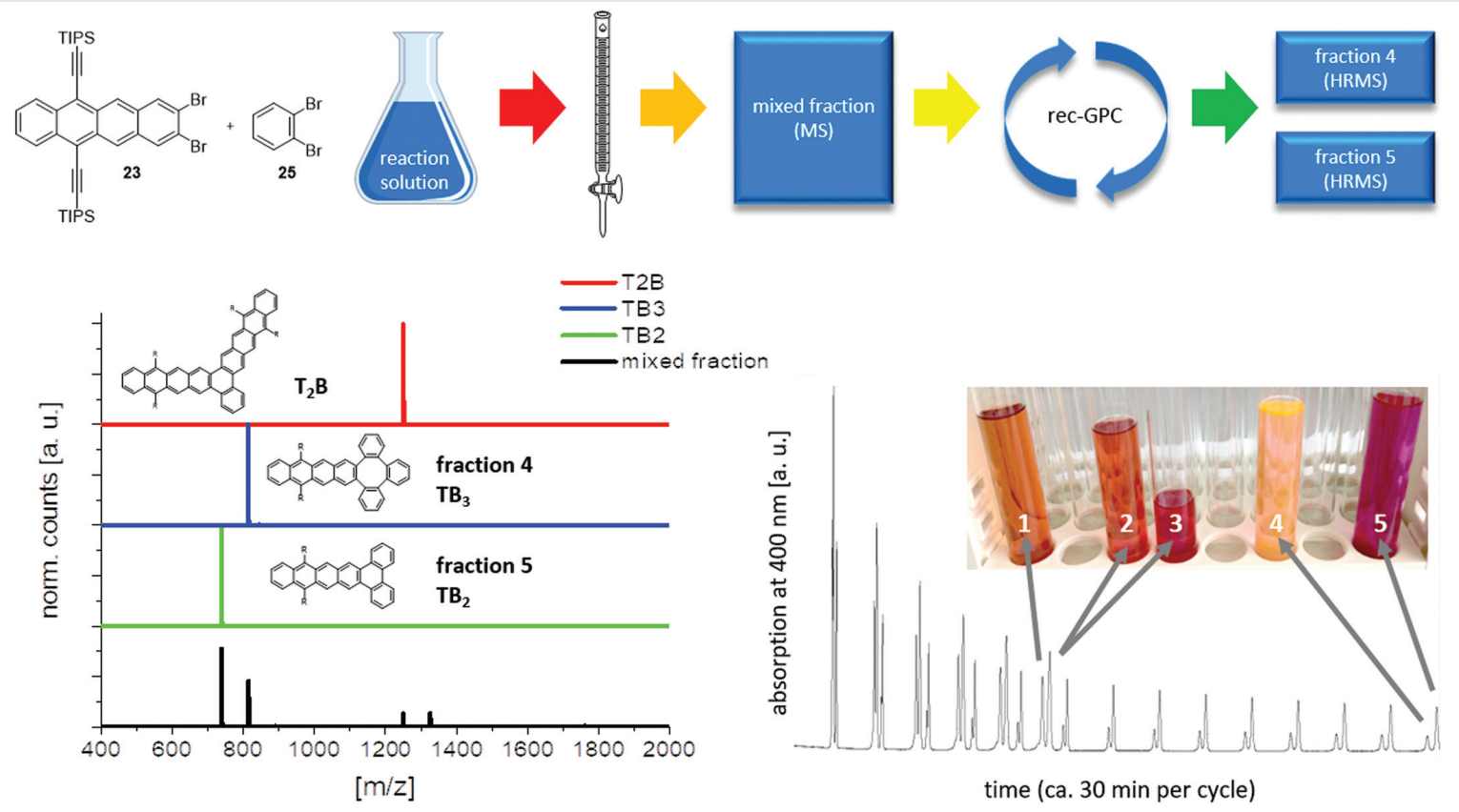

Figure 9 Separation and isolation of different phene types: after synthesis the first purification step involved a standard silica chromatography to remove salts, ligands, and polymers. The MS spectrum (black) shows a mixture of four species with almost the same polarity. These components were separated by employing a recycling GPC, running 14 cycles to achieve baseline separation giving satisfying HR-MS spectra (red, blue, and green).
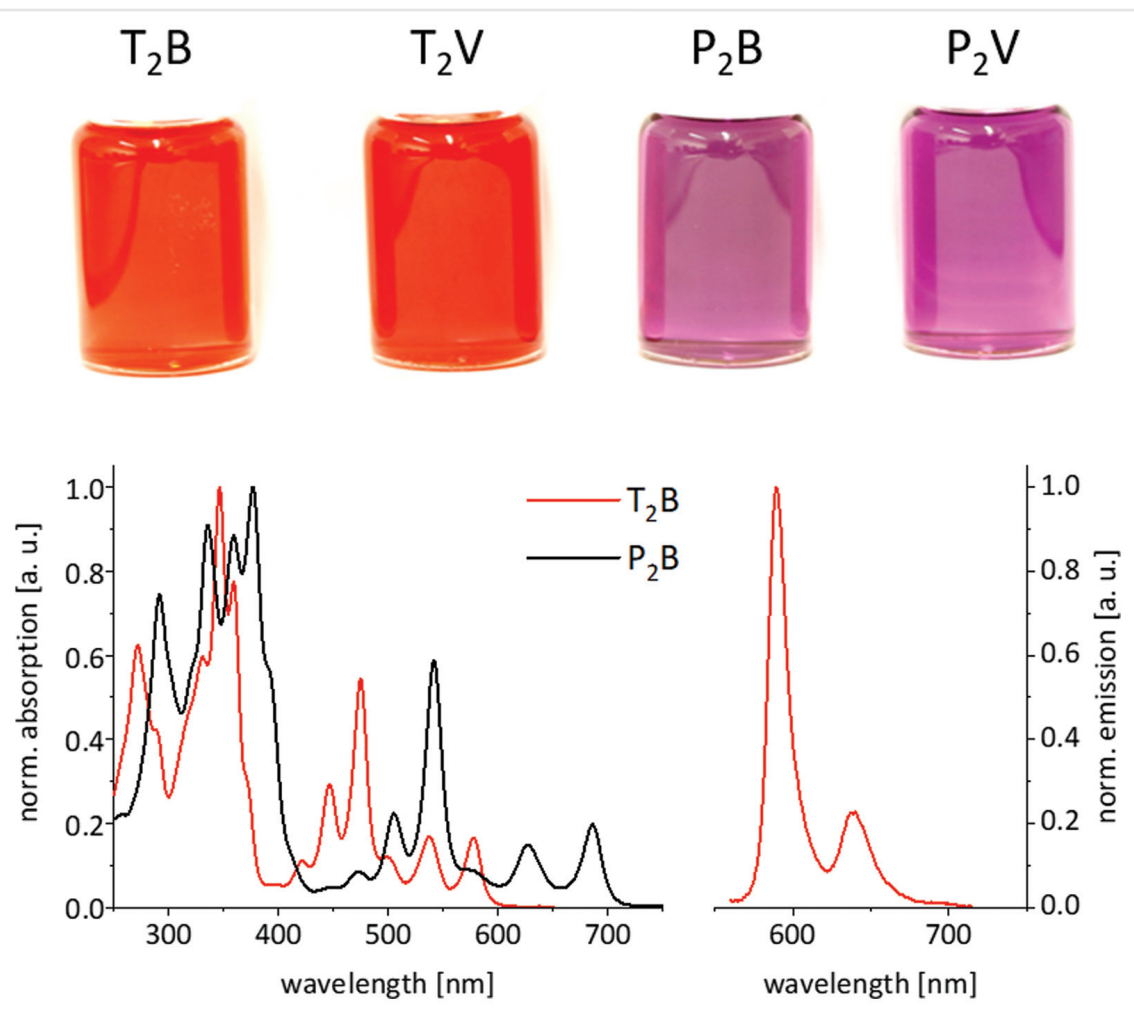

Figure 10 Photographs of phenes $\mathbf{T}_{2} \mathbf{B}, \mathbf{T}_{2} \mathbf{V}, \mathbf{P}_{2} \mathbf{B}$, and $\mathbf{P}_{2} \mathbf{V}$ in $n$-hexane at room temperature (top); $U$-vis spectra of $\mathbf{T}_{2} \mathbf{B}$ and $\mathbf{P}_{\mathbf{2}} \mathbf{B}$ (bottom) are similar to those reported by Clar for unsubstituted phenes. (Adapted with permission from Rüdiger et al. ${ }^{57}$ Copyright 2018 John Wiley and Sons.) 
respectively. There are no conventional synthetic accesses for such tetrabenzocyclooctatetraene scaffolds, although Yamaguchi et al. combined a flexible cyclooctatetraene core with two aceneimide wings. ${ }^{58}$ Our shotgun approach is a superb exploratory tool but, unfortunately, it does not allow the isolation of single products in larger amounts.

Figure 10 displays photographs and UV-vis spectra of solutions of the air-stable benzannulated phenes $\mathbf{T}_{\mathbf{2}} \mathbf{B}$ and $\mathbf{P}_{\mathbf{2}} \mathbf{B}$. The bands are similar to those predicted by Clar's halfempiric formula, despite the presence of the solubilizing TIPS-ethynyl groups. Also, the veratryl compounds display a slightly redshifted absorption: $\mathbf{T}_{\mathbf{2}} \mathbf{B}$ versus $\mathbf{T}_{\mathbf{2}} \mathbf{V}: 8 \mathrm{~nm}$ $\left(237 \mathrm{~cm}^{-1}\right)$ and $\mathbf{P}_{\mathbf{2}} \mathbf{B}$ versus $\mathbf{P}_{\mathbf{2}} \mathbf{V}: 8 \mathrm{~nm}\left(168 \mathrm{~cm}^{-1}\right)$. Calculations show that, due to the deviation from planarity, the degeneracy of the HOMOs and the LUMOs (which are positioned on the acene backbones) is lifted, and that there is-as anticipated-only a fairly small interaction between the acene arms. For both $\mathbf{T}_{\mathbf{2}} \mathbf{B}$ and $\mathbf{P}_{\mathbf{2}} \mathbf{B}$, the conjugation over the central ring causes a bathochromic shift of $43 \mathrm{~nm}$ (1396 $\mathrm{cm}^{-1} / 974 \mathrm{~cm}^{-1}$ ) compared to TIPS-Tet and TIPS-Pen, respectively. The energy gap derived from the absorption onset at the lowest energy $\left(\mathbf{T}_{\mathbf{2}} \mathbf{B}: 2.09 \mathrm{eV}\right)$ is in good agreement with the gap $(1.99 \mathrm{eV})$ predicted by quantum chemical calculations [DFT, BP86 def2-TZCP // B3LYP, 6$311++\mathrm{G}(\mathrm{d}, \mathrm{p})]$.

In 1964, Clar published a semiempiric equation to predict the position of the lowest absorption band ( $\alpha$ band) of phenes. ${ }^{37}$ Equation 1 was based on the spectroscopic data available at that time and considers an excitation mechanism adapted from the Bohr model with the Rydberg constant $\left(R_{\infty}\right)$. The excited $\pi$-electron was considered to be influenced by two carbon atoms $\left(2 \times 6\right.$ nuclear charges; $\left.12^{2}\right)$.

$$
v_{\alpha}=\frac{12^{2} R_{\infty}}{\mathrm{K}^{2}}\left(\frac{1}{2^{2}}-\frac{1}{3^{2}}\right) \lambda_{\alpha}=\frac{\mathrm{K}^{2}}{20 R_{\infty}} \quad(\text { Equation 1) }
$$

The order " $K$ " starts with the value 6 for benzene and increases by 0.5 for every ring added to the system. For the new, enlarged phenes presented by our group, the benzannulated ring has to be left out because the lowest

Table 1 Comparison of the position of the $\alpha$-band as predicted by Clar with experimental values.

\begin{tabular}{lllll}
\hline & Pentaphene & Heptaphene & $\mathrm{T}_{2} \mathrm{~B}$ & $\mathrm{P}_{2} \mathrm{~B}$ \\
\hline$K$ & 9.5 & 10.5 & 11.5 & 12.5 \\
Calculated by Clar & $411 \mathrm{~nm}$ & $503 \mathrm{~nm}$ & $603 \mathrm{~nm}$ & $712 \mathrm{~nm}$ \\
Experimental & $417 \mathrm{~nm}^{\mathrm{a}}$ & $486 \mathrm{~nm}^{\mathrm{a}, \mathrm{b}}$ & $577 \mathrm{~nm}$ & $686 \mathrm{~nm}$ \\
Deviation & $6 \mathrm{~nm}$ & $17 \mathrm{~nm}$ & $26 \mathrm{~nm}$ & $26 \mathrm{~nm}$ \\
& $+1.5 \%$ & $-3.4 \%$ & $-4.3 \%$ & $-3.7 \%$ \\
\hline
\end{tabular}

${ }^{\mathrm{a}}$ Ref. $^{37}$

${ }^{\mathrm{b}}$ Absorption of benzoheptaphene. energy absorption band only depends upon the two longest arms. With this in mind, the correct order $(K)$ for $\mathbf{T}_{\mathbf{2}} \mathbf{B}$ and $\mathbf{P}_{\mathbf{2}} \mathbf{B}$ is 11.5 (9 rings) and 12.5 (11 rings), respectively. Although absorption features may be influenced by the TIPS-alkynyl substituents on the larger arms, calculations according to Clar's formula show a surprisingly small deviation of less than $5 \%$ (Table 1).

Geometry optimization with DFT methods results in nonplanar structures of the benzannulated phenes due to the steric repulsion of the silyl alkynyl substituents-the deviation from planarity lifts the degeneracy of the frontier molecular orbitals, which would be expected for entirely flat species. Both frontier molecular orbitals (Figure 11) are spread out over two arms, suggesting a type of metaconjugation. Crystal structure analyses also emphasize nonplanarity of the phenes. $\mathbf{T}_{\mathbf{2}} \mathbf{V}$ and $\mathbf{P}_{\mathbf{2}} \mathbf{V}$ both form isolated pairs of molecules, nonoverlapping with other pairs via $\pi-\pi$ interactions as they are separated by the solvent included in the unit cells.

Figure 12 displays the UV-vis spectra of $\mathbf{T B}_{\mathbf{3}}$ and $\mathbf{T}_{\mathbf{2}} \mathbf{V}_{\mathbf{2}}$, and a photograph of an amorphous film of red $\mathbf{T}_{2} \mathbf{V}_{\mathbf{2}}$ on polyimide. In the case of the cyclooctatetraene derivatives, the arms are fully decoupled, as their p-bands are almost

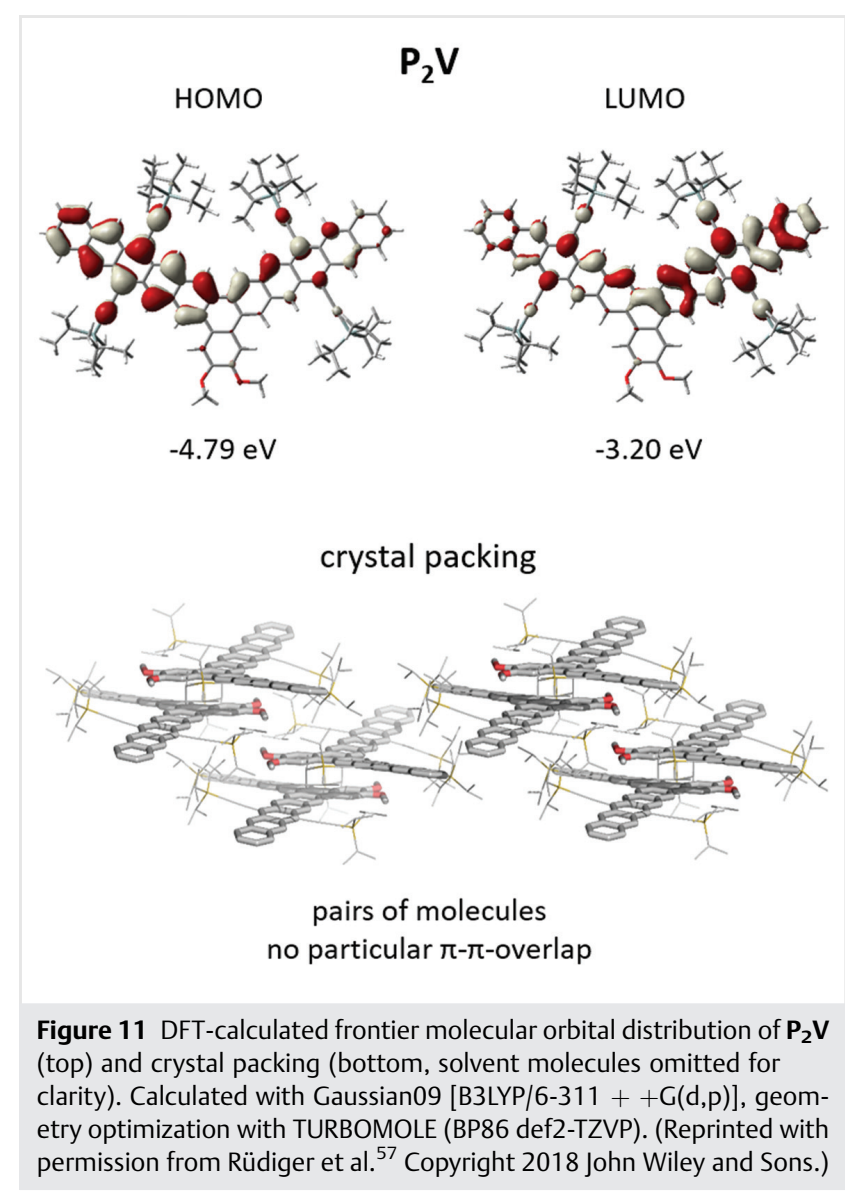


superimposable. Therefore, the geometry enforced by the cyclooctatetraene core insulates the arms from each other (cf. Table 2). This is not the case in the cyclotrimers $\mathbf{P B}_{\mathbf{2}}$ and of $\mathbf{P V}_{\mathbf{2}}$, where the central benzene ring is planar and some interaction is observable, testimony to the bathochromic absorption compared to the parent acenes. Additionally, the veratrole derivatives exhibit redshifted absorption bandsvisible in solutions of $\mathbf{T B}_{\mathbf{2}}$ and $\mathbf{T V}_{\mathbf{2}}$, which displays clearly different colors (Figure 13).

Figure 14 displays a synopsis of the absorption maxima of the different substituted acenes and their dibenzoequipped analogs as well as that of a biphenylated pentacene (26) for comparison. The dibenzo-"aprons" render the outermost benzene ring-embedded in a triphenylene unit-less acene-like. However, the maximum absorption of $\mathbf{P B}_{\mathbf{2}}$ for example is roughly in the middle in comparison to the one of TIPS-Pen as well as the one of a similarly substituted hexacene. This suggests that the benzene ring participates electronically in the large acene system. Otherwise, $\mathbf{P B}_{\mathbf{2}}$ would resemble TIPS-Pen or the twisted model compound $\mathbf{2 7}$ much more. Some of the hexacene-like character is preserved in $\mathbf{P B}_{\mathbf{2}}$ and $\mathbf{P} \mathbf{V}_{\mathbf{2}}$, despite the benzo-aprons, in good agreement with Clar's early observations. ${ }^{37}$ Other groups have also introduced additional Clar sextets via annulation strategies to stabilize the higher (aza)arenes. ${ }^{31,59-61}$ However, the mode of annulation $^{62}$ is crucial, as otherwise the optoelectronics of such species differ from those of unsubstituted acenes.

The synthesis of processible, soluble, and stable $\mathbf{P B}_{\mathbf{2}}$ and its congeners was an attractive achievement, but to fabricate thin film transistors, more material was needed; the amount obtained from the statistical Yamamoto coupling was insufficient.

A direct synthesis of $\mathbf{P B}_{\mathbf{2}}$ started with the bisborylated biphenyl 28 (Scheme 4), which was coupled to dibromoacenes 23/24. Monocoupled products resulted after Suzuki
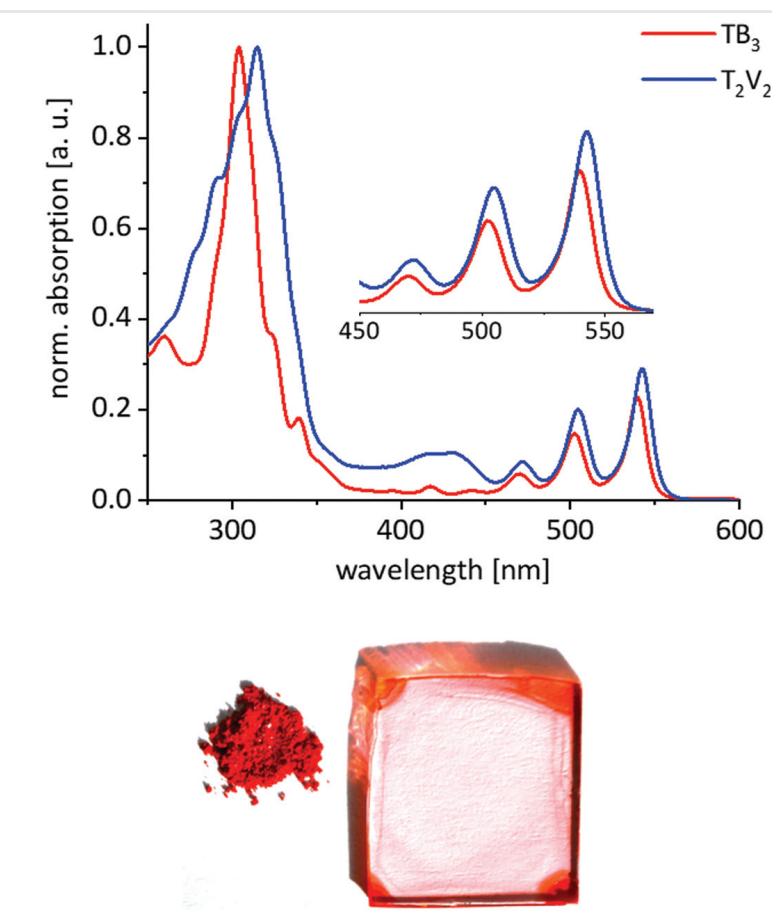

Figure $12 \mathrm{UV}$-vis spectra of $\mathrm{TB}_{\mathbf{3}}$ and $\mathbf{T}_{\mathbf{2}} \mathbf{V}_{\mathbf{2}}$ (top), and photograph of an amorphous film of $\mathbf{T}_{\mathbf{2}} \mathbf{V}_{\mathbf{2}}$ on polyimide-coated glass (bottom).

reaction-partial deborylation of the former biphenyl moiety was the culprit. In the case of the nonmethoxylated system, C-H activation did not occur even with a more active catalyst. In contrast, the more electron-rich veratrylenes $\mathbf{T V}_{\mathbf{2}}$ and $\mathbf{P} \mathbf{V}_{\mathbf{2}}$ were obtained via this strategy, although as a mixture of constitutional isomers. The position of the methoxy groups in $\mathbf{3 0 / 3 2}$ was dependent upon which $\mathrm{C}-\mathrm{H}$ bond was activated.

Table 2 Optical and electronic properties of selected cyclooligomers in comparison with their parent congeners.

\begin{tabular}{|c|c|c|c|c|c|c|c|}
\hline Compound & $\lambda_{\max , a b s}[n m]^{a}$ & $\lambda_{\max , \mathrm{em}}[\mathrm{nm}]^{\mathrm{b}}$ & Gap $[\mathrm{nm} / \mathrm{eV}]^{\mathrm{c}}$ & $\phi_{\mathrm{f}}[\%]^{\mathrm{d}}$ & Calcd. $E_{\text {номо }}[\mathrm{eV}]^{\mathrm{e}}$ & Calcd. $E_{\mathrm{LUMO}}[\mathrm{eV}]^{\mathrm{e}}$ & Calcd. gap $[\mathrm{eV}]^{\mathrm{e}}$ \\
\hline $\mathrm{TB}_{3}$ & 540 & 543 & $552 / 2.25$ & 60 & -5.10 & -2.84 & 2.26 \\
\hline $\mathrm{PB}_{3}$ & 645 & 649 & 659 / 1.88 & 65 & -4.88 & -3.06 & 1.82 \\
\hline $\mathrm{T}_{2} \mathrm{~V}_{2}$ & 542 & 546 & 554 / 2.24 & 25 & $-4.90^{f}$ & $-2.68^{f}$ & $2.22^{f}$ \\
\hline PVPV & 648 & 653 & $663 / 1.87$ & - & $-4.66^{f}$ & $-2.91^{f}$ & $1.75^{f}$ \\
\hline TIPS-Tet & $534^{54}$ & $540^{54}$ & & $79^{54}$ & -5.09 & -2.80 & 2.29 \\
\hline TIPS-Pen ${ }^{\mathrm{e}}$ & $643^{53}$ & $650^{53}$ & & $75^{53}$ & -4.91 & -3.08 & 1.83 \\
\hline
\end{tabular}

${ }^{a}$ Absorption peak at the lowest energy in $n$-hexane.

bEmission peak in $n$-hexane.

'Optical gap derived from absorption onset at the lowest energy.

${ }^{\mathrm{d}}$ Absolute fluorescence quantum yield in $n$-hexane.

e Calculated with Gaussian09 ${ }^{65}$ [B3LYP/6-311 + +G(d,p)], geometry optimization with TURBOMOLE, (BP86 def2-TZVP).

fTIPS substituents replaced by TMS for simplicity. 

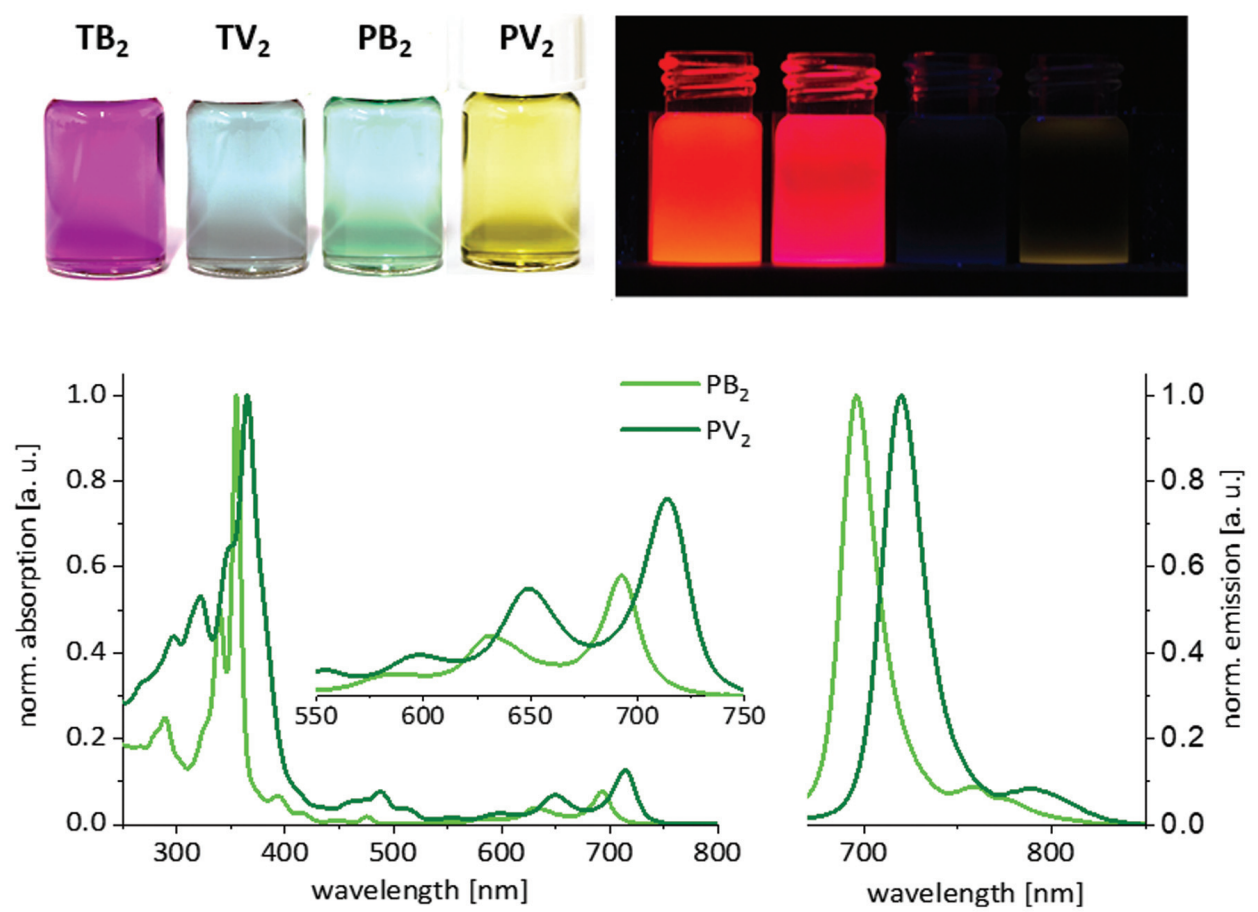

Figure 13 Photographs of $\mathbf{T B}_{2}, \mathbf{T V}_{\mathbf{2}}, \mathbf{P B}_{\mathbf{2}}$, and $\mathbf{P V}_{\mathbf{2}}$ in $n$-hexane (from left to right) under ambient light (top left) and under UV-light (365 nm, top right), and UV-vis spectra of $\mathbf{P B}_{\mathbf{2}}$ and $\mathbf{P V}_{\mathbf{2}}$ (bottom). (Adapted with permission from Rüdiger et al. ${ }^{57}$ Copyright 2018 John Wiley and Sons.)

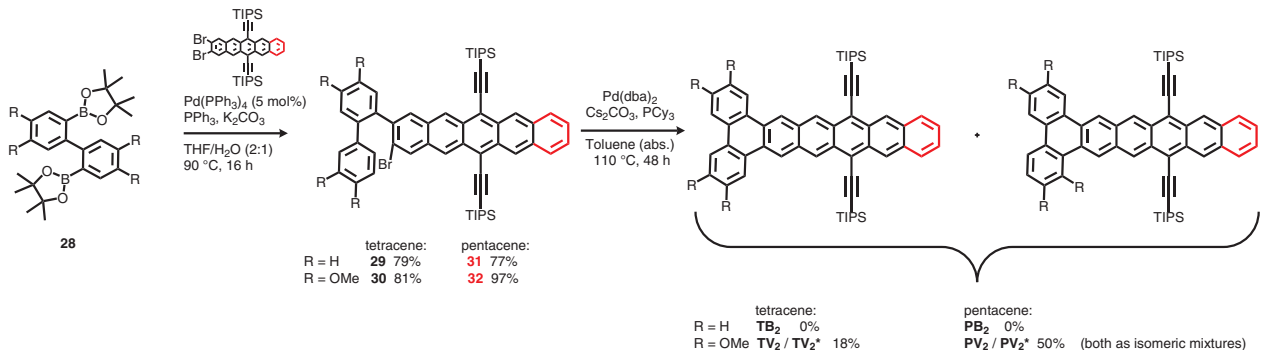

Scheme 4 Synthesis of dibenzo-substituted tetracenes and pentacenes using Suzuki coupling.

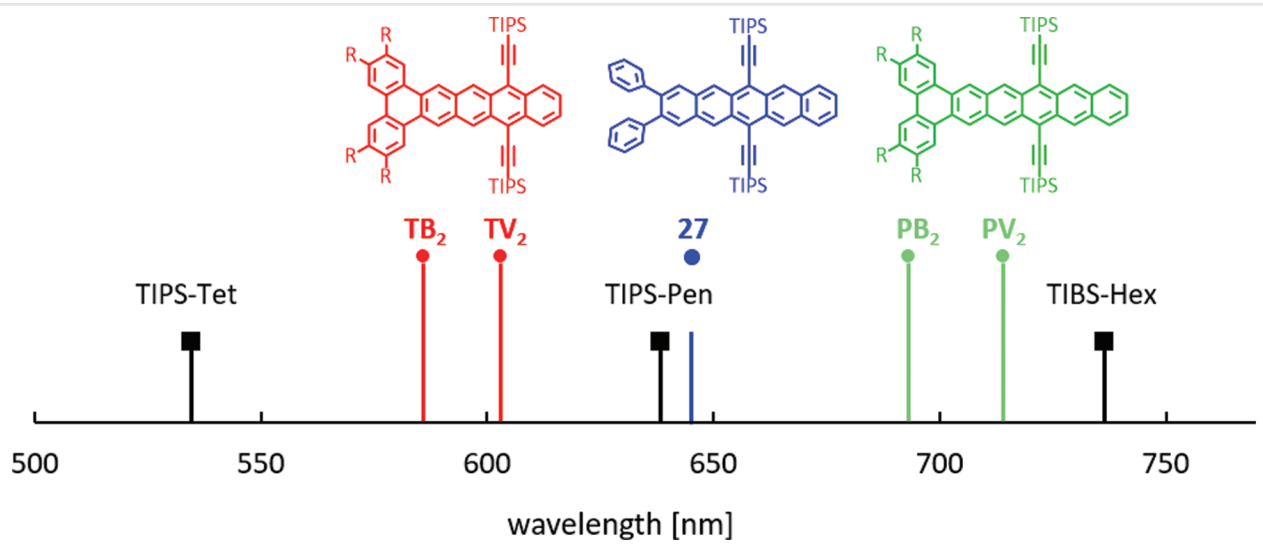

Figure 14 Maximum absorptions [nm] of different acenes and benzannulated pentacenes and hexacenes compared to TIPS-Tet, TIPS-Pen, and a hexacene (TIBS-Hex). 


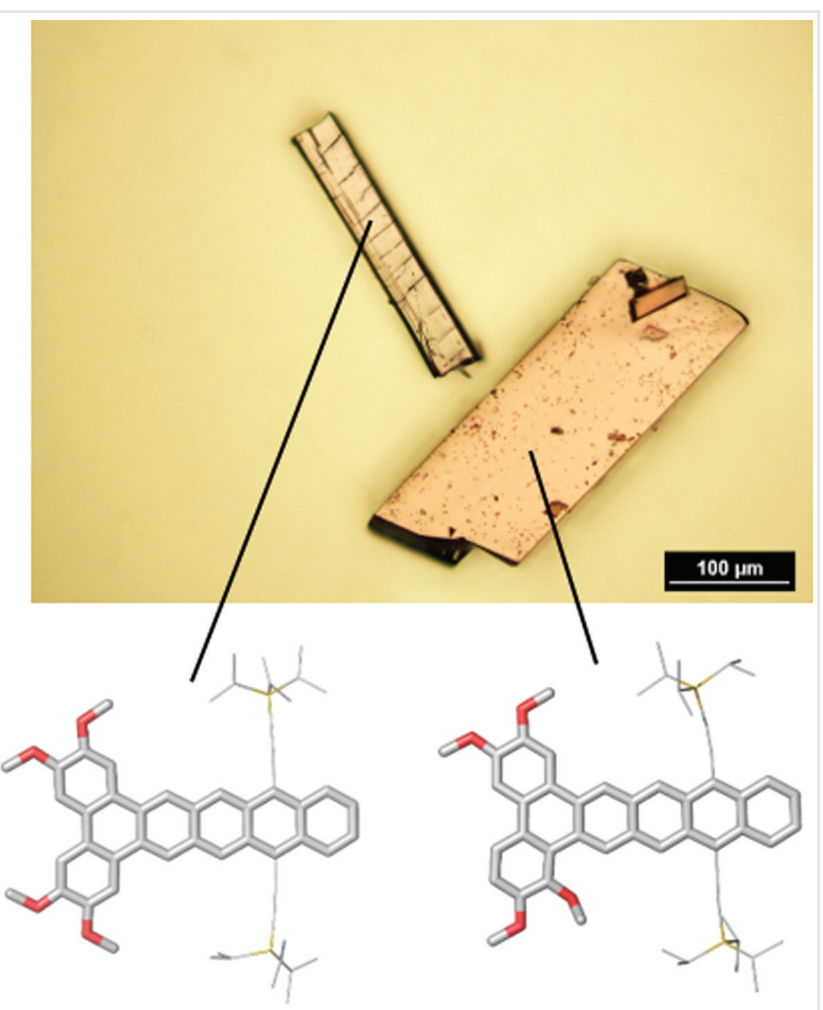

Figure 15 Two different single crystals formed by the two different stereoisomers $\mathbf{T V}_{\mathbf{2}}$ and $\mathbf{T V}_{\mathbf{2}}{ }^{*}$.

Chromatographic separation was difficult, but crystallization of the fairly air-sensitive species (decoloration of solutions occurred within 1 to 2 days under ambient conditions) rendered two different types of single crystals (Figure 15), which, after manual separation and successful X-ray analysis, were identified as $\mathbf{T V}_{\mathbf{2}}$ and $\mathbf{T V}_{\mathbf{2}}{ }^{*}$, allowing to characterize both isomers structurally.

This two-step approach (i.e. the inability to close the ring in one shot), the need for electron-rich arenes for $\mathrm{CH}$ activations, and the problems with the regioselectivity made this method less than ideal for the preparation of larger amounts of $\mathbf{P B}_{\mathbf{2}}$ or $\mathbf{T B}_{\mathbf{2}}$. The literature known $\mathrm{Sn}, \mathrm{Sn}$ dimethylstannafluorene (Scheme 5) offered a solution. In a Stille-type reaction of the stannafluorene with the tetracene- and pentacene-dibromides, we obtained $\mathbf{T B}_{\mathbf{2}}$ and $\mathbf{P B}_{\mathbf{2}}$ in 57 and $77 \%$ yields, respectively. ${ }^{63}$ Larger amounts of $\mathbf{P B}_{\mathbf{2}}$ were easily accessible for applications. Figure 16 displays the molecular structures of $\mathbf{P B}_{\mathbf{2}}$ and $\mathbf{P} \mathbf{V}_{\mathbf{2}}$. $\mathbf{P B}_{\mathbf{2}}$ packs in a herringbone motif with head-to-tail dimers. The molecules form two-dimensional layers, separated by their TIPSethynyl side chains. The packing of $\mathbf{P V}_{\mathbf{2}}$ displays similar spatial separation induced by the TIPS-ethynyl groups, but the molecules form a brick-wall motif with alternating orientations of the biarylene moieties in subsequent layers.

A p-channel bottom-contact/top-gate transistor with $\mathbf{P B}_{2}$ displays mobilities up to $0.20 \mathrm{~cm}^{2} /(\mathrm{Vs})$. Spin coated from tetraline solution, $\mathbf{P B}_{\mathbf{2}}$ forms crystalline thin films, while $\mathbf{P V}_{\mathbf{2}}$ stays amorphous as a film.

Tetrabromoanthracene or tetrabromopentacene reacts (palladium-catalyzed) with the stannafluorene (Scheme 6) to form tetrabenzopentacene (38\%) and tetrabenzoheptacenes (8-24\%) as stable and crystalline materials. ${ }^{64}$ The facile synthesis and workup allows the preparation of such acene-types in a one-shot reaction and if necessary in gram quantities.

Figure 17 displays the UV-vis absorption spectra of $\mathbf{T B}_{\mathbf{2}}$ (blue), $\mathbf{P B}_{\mathbf{2}}$ (teal), $\mathbf{A B}_{\mathbf{4}}$ (red), and $\mathbf{P B}_{\mathbf{4}}$ (dark green) in solution. $\mathbf{A B}_{\mathbf{4}}$ shows the most blueshifted absorption, and it displays similar absorption features to a tetracene. This is followed by $\mathbf{T B}_{\mathbf{2}}, \mathbf{P B}_{\mathbf{2}}$, and $\mathbf{T B}_{4}$, the last one being a formal heptacene, yet absorbing in the same range as would be expected for a hexacene. In this case again, each triphenylene unit has a similar electronic effect as a half of a benzene ring.

Attempts to grow single crystals for the symmetrical species were only successful for $\mathbf{A B}_{\mathbf{4}}$; structure and packing are shown in Figure 18. One polymorph shows an ideal brick-wall motif, with the triphenylene units overlapping. The high crystallinity of the material resulted in dewetting

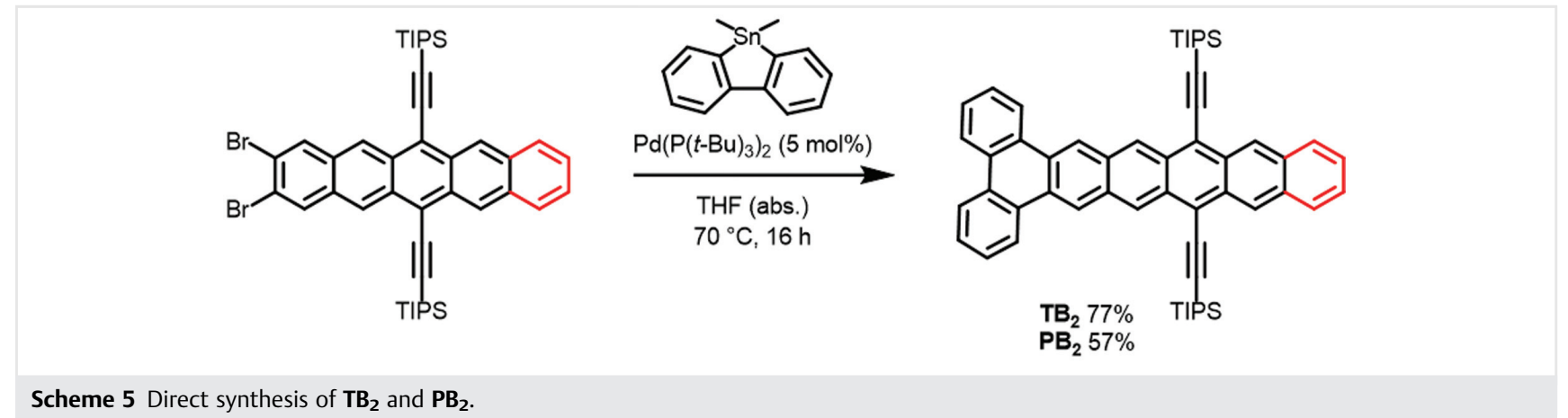

Scheme 5 Direct synthesis of $\mathrm{TB}_{\mathbf{2}}$ and $\mathbf{P B}_{\mathbf{2}}$. 

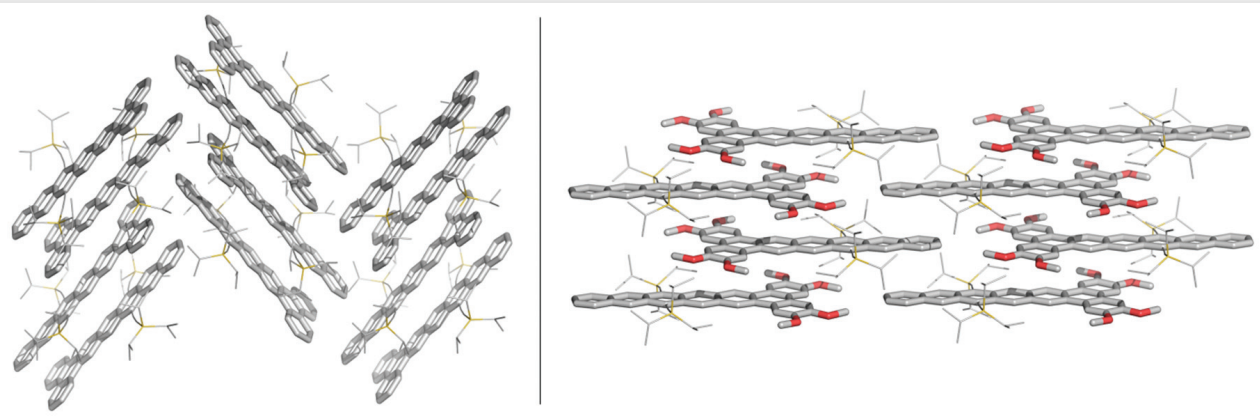

Figure 16 Crystal structures of $\mathbf{P B}_{\mathbf{2}}$ (left) and $\mathbf{P V}_{\mathbf{2}}$ (right) obtained from THF/MeOH diffusion crystallization. ${ }^{68}$ (Reprinted with permission from Rüdiger et al. ${ }^{63}$ Copyright 2018 John Wiley and Sons.)

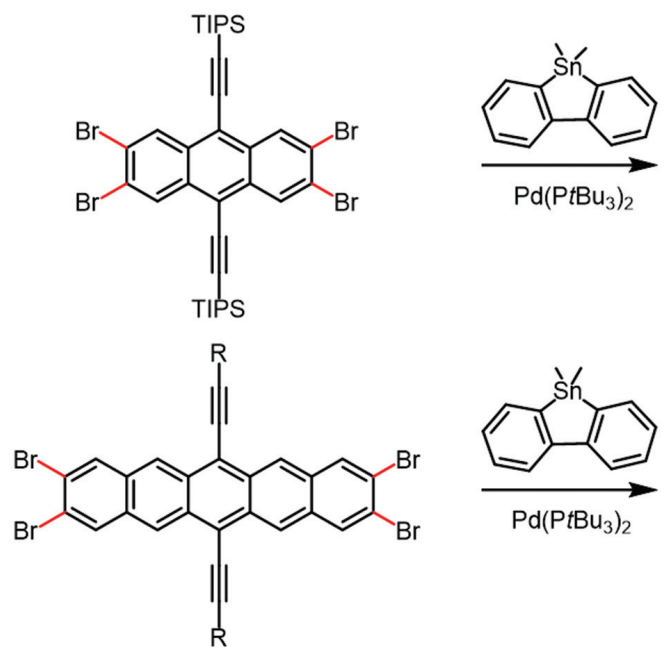

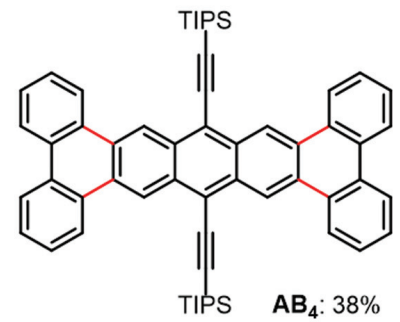<smiles></smiles>

$\mathrm{PB}_{4}$ : a: $18 \%$, b: $8 \%$, c: $24 \%$

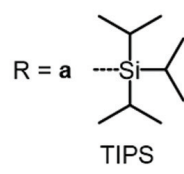

b<smiles>CCC(C)C(C)C(C)CC</smiles>

c<smiles>CC(C1CCCC1)(C1CCCC1)C1CCCC1</smiles>

Scheme 6 Stille-type synthesis of tetrafold benzannulated acenes using a stannafluorene and a highly active Pd-catalyst.

from all tested substrates, so the fabrication of thin-film transistors was challenging. In early experiments, $\mathbf{A B}_{\mathbf{4}}$ displayed singlet fission, currently under investigation. Derivatives of $\mathbf{P B}_{\mathbf{4}}$ were not soluble enough, even with enlarged trialkylsilyl groups, to give a suitable single crystalline specimen or make thin-film transistors. These are challenges still to be met.
To investigate the aromaticity of our benzannulated systems, we performed NICS calculations (Figure 19). While the acene units are all fairly inconspicuous in their aromaticity, compared to TIPS-Pen, the central rings formed upon annulation are almost nonaromatic, to a higher extent than the central ring in triphenylene. This arrangement maximizes the number of Clar sextets, i.e. one per acene or 


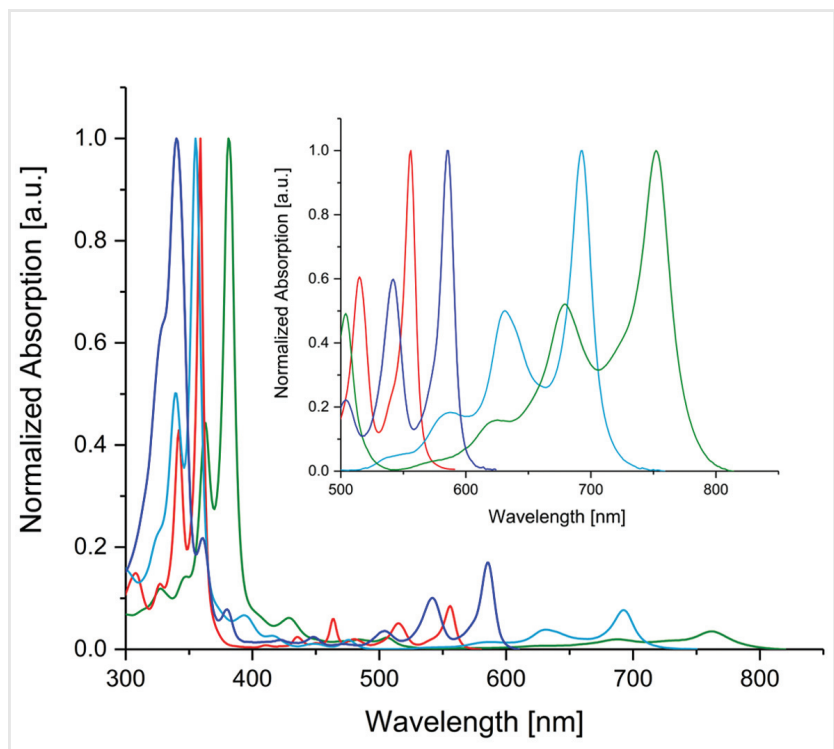

Figure 17 UV-vis absorption spectra of $\mathbf{T B}_{\mathbf{2}}$ (blue), $\mathbf{P B}_{\mathbf{2}}$ (teal), $\mathbf{A B}_{\mathbf{4}}$ (red), and $\mathbf{P B}_{\mathbf{4}}$ (dark green) in $n$-hexane at room temperature. (Reprinted with permission from Müller et al. ${ }^{64}$ Copyright 2018 John Wiley and Sons.)

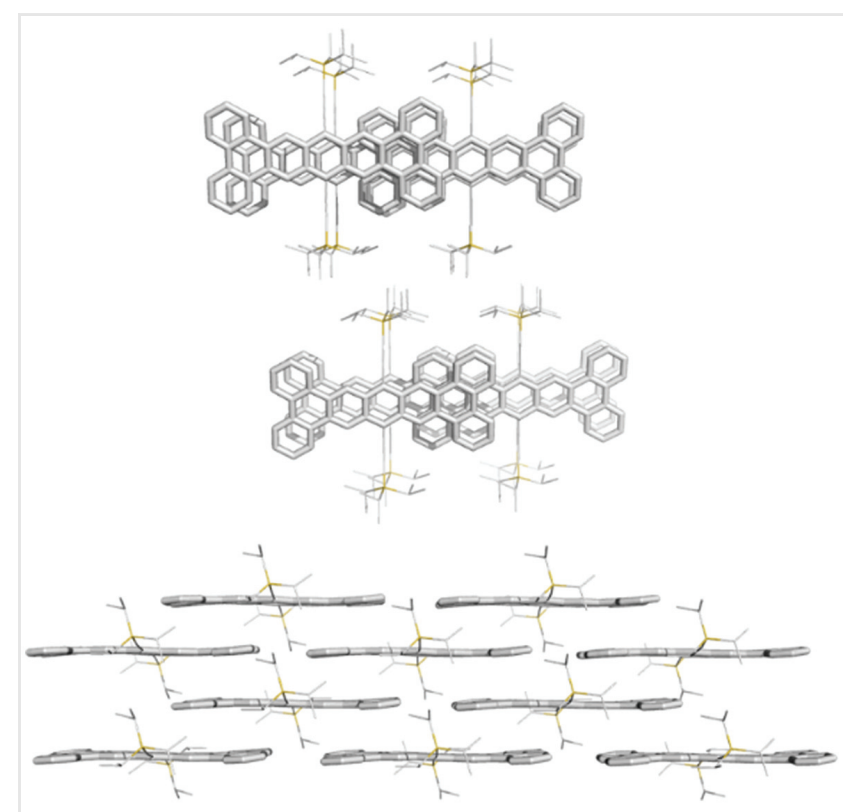

Figure 18 Solid-state packing of the classic brick-wall polymorph of $\mathbf{A B}_{4}{ }^{69}$ (Reprinted with permission from Müller et al. ${ }^{64}$ Copyright 2018 John Wiley and Sons.)

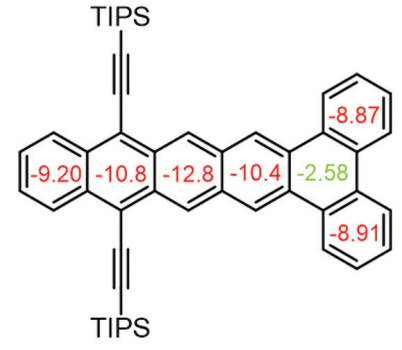

$\mathrm{TB}_{2}$

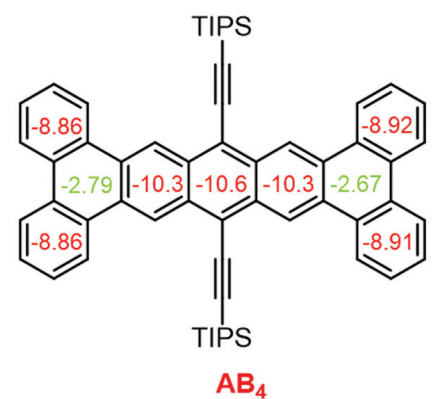<smiles>FC(F)(F)C#Cc1c2cc3ccccc3cc2c(C#C[AsH-])c2cc3cc4c5ccccc5c5ccccc5c4cc3cc12</smiles>

$\mathrm{PB}_{2}$

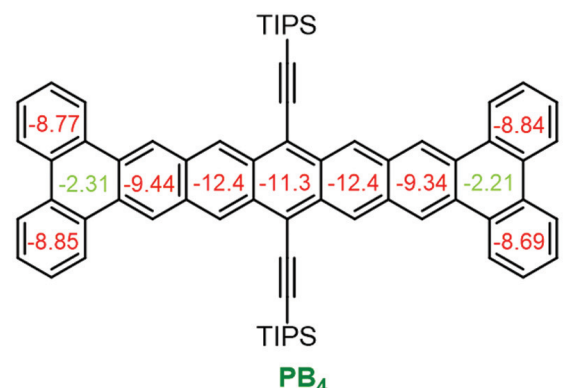

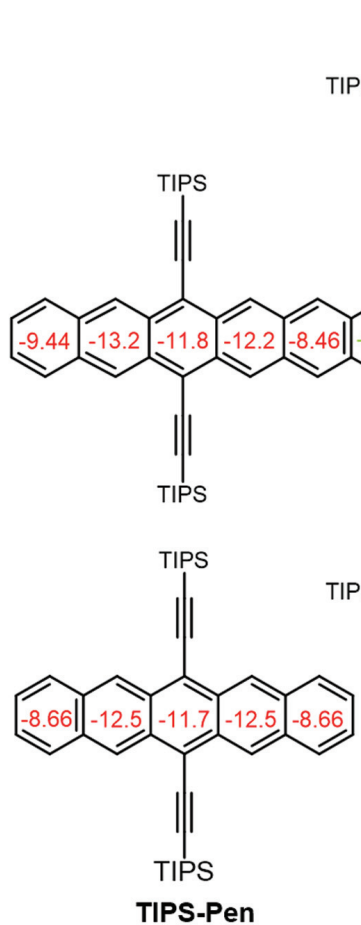

TIPS<smiles>CC=C1CC2C=CC=C1CC2</smiles><smiles>CC1=C(C)C2C=CC(=C1)C2</smiles><smiles>[C+]1=CC=C1</smiles><smiles>[C]1CCC1</smiles><smiles>[C]1C=[C+]C1</smiles>

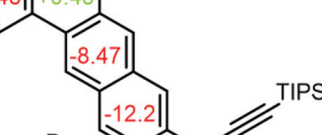

$\mathrm{P}_{3}$

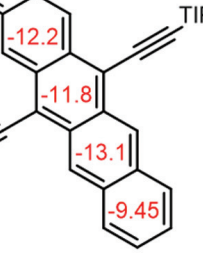

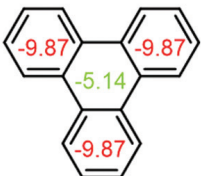

triphenylene

Figure 19 NICS(1) values calculated at the B3LYP/6-311++ G(d,p) level. ${ }^{65}$ 
benzene arm, and it is the most stable one energetically. The inner benzene rings are aromatic with NICS(1) values of -9 to $-13 \mathrm{ppm}$. The central triphenylene rings are essentially nonaromatic with NICS(1) values of around $-2.5 \mathrm{ppm}$. This again highlights the specific nature of these rings which are not fully integrated into the electronics of the larger acene system, as they are only peripherally conjugated. The NICS values support the picture obtained by distributing Clar

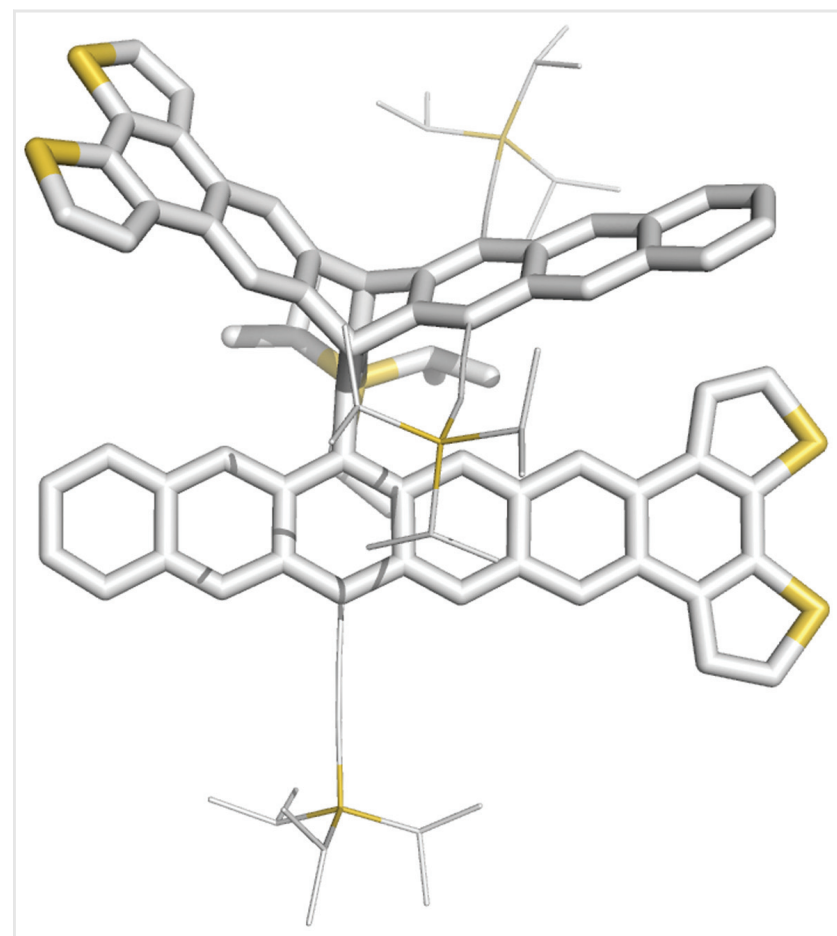

Figure 20 Single-crystal structure of the dimer of bisthienyl-annulated hexacene (D-PTh $\mathbf{2}_{\mathbf{2}}$ ). TIPS-ethynyl substituents have been reduced in size for clarity. ${ }^{70}$

sextets. To maximize their numbers, e.g. in $\mathbf{T B}_{2}$, the two benzo units are assigned to a Clar sextet each, leaving the central ring of the formal triphenylene subunit Clar-sextet-less.

The benzannulated species were much more stable in solution under ambient conditions and even under irradiation than their non-benzo-appended congeners, and could be handled in the solid state for indefinite periods of time. However, the more electron-rich thienomoieties decrease the stability of the materials. During the Stille reaction to $\pi$-extend dibromopentacene $\mathbf{2 4}$, the resulting bis-thieno-annulated species underwent in situ Diels-Alder cycloaddition solely furnishing its dimer DPTh $_{2}$ (Figure 20).
The correct choice of stabilizing aprons such as phenyl rings should allow the preparation of even larger acenes, yet, of course, issues with solubility and processability will increase with growing size. These are tackled by the addition of alkyl or oligo(ethylene glycol) chains or similar units, but these substituents are nonsemiconducting and might curtail efficient charge transport in the solid state, unless clever crystal engineering is employed to ensure their electronic interaction.

\section{Conclusions and Outlook}

Starting from the synthesis of the symmetrical starphenes, a whole group of new phene-type molecules were synthesized and characterized. While some of the parents have been made by Clar, their soluble, characterizable derivatives have been unknown. We have developed new synthetic approaches towards substituted phenes, using Yamamoto coupling protocols as divining rods towards such species-sometimes via a shotgun approach. For the selective synthesis, particularly of dibenzo- or triphenylene-type species such as $\mathbf{P B}_{\mathbf{2}}$, etc., coupling of a stannafluorene in a Stille-type reaction to a dibromoarene is the method of choice. Reasonable yields and the efficient construction of a single material are ensured, making such species available in larger quantities.

In the future we will prepare $\pi$-extended stannafluorenes (Scheme 7), which are powerful precursors to longarm starphenes. It is not clear at all how such $\mathrm{H}$-shaped species react, and how long the phene-arms can be made without running into problems of stability and processability. Also, one can change the size and nature (by heteroatom doping) of the internal acene unit to investigate the influence of the central unit on the electronic and solidstate properties of the arms.

In the end, the flow diagram in Figure 21 delineates our approach to materials and property prospecting. Starting with a shotgun synthesis of novel species involving separation and characterization, we might find one or several attractive targets, which could be investigated for example for charge transport properties, etc. In the next round of such a refinement cycle, we would develop a more efficient method for the synthesis of the targets under consideration to study their optoelectronics in more detail and jointly investigate them with our collaborators who will use them in OLEDs or in photovoltaic cells.

Overall there is a large structural space of aromatic compounds to be explored, in which novel synthetic methods, smoothly designed for solubilizing appendages, and previously unknown structures form an exciting materials science cauldron from which (hopefully) stable, 

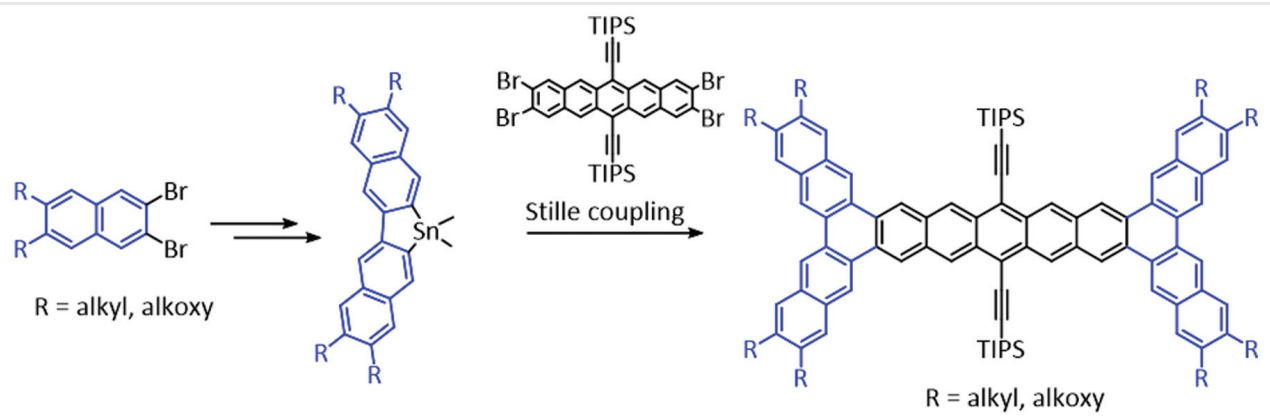

Scheme 7 Synthesis of enlarged double starphenes.

\section{Exploratory Synthesis}
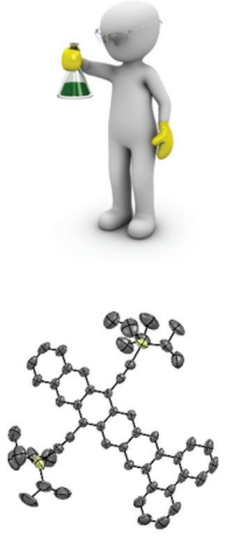

\section{Analysis}
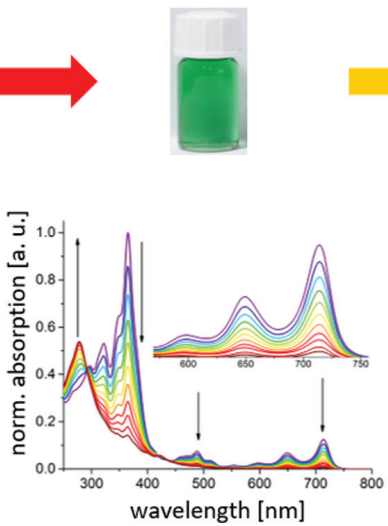

Transistor
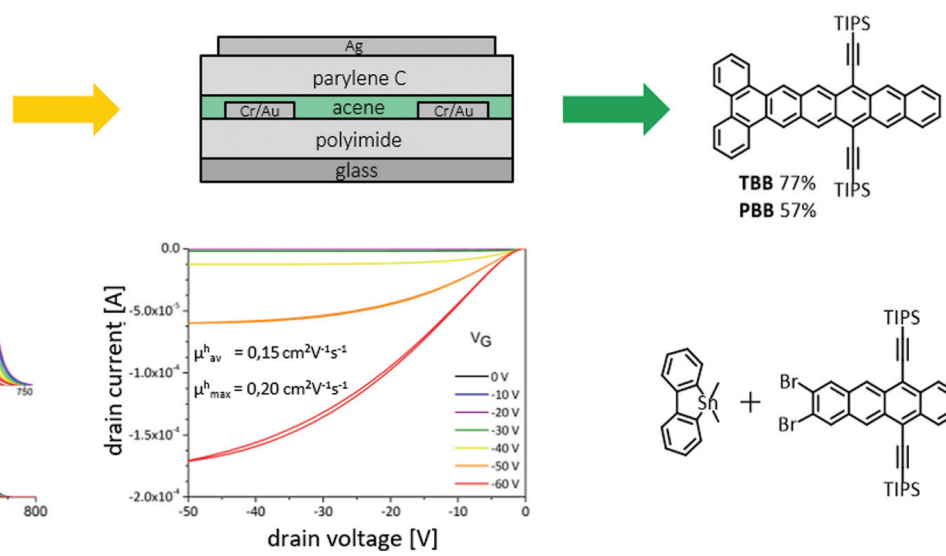

Selective synthesis

Figure 21 Workflow, optimizing materials, and property discovery using starphenes. (Parts of Figure 21 adapted with permission from Rüdiger et al. ${ }^{63}$ Copyright 2018 John Wiley and Sons.)

processible, and easily prepared materials with amazing properties are extractable.

\section{Funding Information}

We thank the DFG (SFB 1249) for generous financial support. Matthias Müller thanks the Fonds der Chemischen Industrie for a PhD scholarship.

\section{Acknowledgement}

We are indebted to Prof. Mastalerz for the use of his preparative gpc and Dr. Frank Rominger for crystal structure analysis. Uwe Bunz thanks all of his coworkers who contributed to the results of this review.

\section{References}

(1) Wegner, G. Angew. Chem. Int. Ed. Engl. 1981, 20, 361-381.

(2) Goodings, E. P.; Mitchard, D. A.; Owen, G. J. Chem. Soc. Perkin. Trans. 1 1972, 1310.

(3) Tsumura, A.; Koezuka, H.; Ando, T. Appl. Phys. Lett. 1986, 49, 1210-1212.

(4) Assadi, A.; Svensson, C.; Willander, M.; Inganäs, O. Appl. Phys. Lett. 1988, 53, 195-197.

(5) Setayesh, S.; Grimsdale, A. C.; Weil, T., et al. J. Am. Chem. Soc. 2001, 123, 946-953.

(6) Ahrens, L.; Schlisske, S.; Strunk, K-P., et al. Chem. Mater. 2018, 30 , 4157-4167. 
(7) Shu, C-F.; Dodda, R.; Wu, F-I.; Liu, M. S.; Jen, A. K-Y. Macromolecules 2003, 36, 6698-6703.

(8) Li, Z.; Xu, X.; Zhang, W., et al. J. Am. Chem. Soc. 2016, 138, 10935-10944.

(9) Horowitz, G.; Kouki, F.; Spearman, P., et al. Adv. Mater. 1996, 8 , 242-245.

(10) Zheng, N.; Mahmood, K.; Zhong, W., et al. Nano Energy 2019, 58, 724-731.

(11) (a) Clar, E. Aromatische Kohlenwasserstoffe. 2nd ed. Springer: Berlin, Heidelberg; 1952. (b) Clar, E.; John, F. Ber. dtsch. Chem. Ges. A/B 1929, 62, 3021-3029. (c) Clar, E.; John, F. Ber. dtsch. Chem. Ges. A/B 1930, 63, 2967-2977.

(12) Dimitrakopoulos, C. D.; Malenfant, P. RL. Adv. Mater. 2002, 14, 99-117.

(13) Sirringhaus, H. Adv. Mater. 2005, 17, 2411-2425.

(14) Klauk, H.; Halik, M.; Zschieschang, U.; Schmid, G.; Radlik, W.; Weber, W. J. Appl. Phys. 2002, 92, 5259-5263.

(15) Anthony, J. E.; Brooks, J. S.; Eaton, D. L.; Parkin, S. R. J. Am. Chem. Soc. 2001, 123, 9482-9483.

(16) Anthony, J. E. Chem. Rev. 2006, 106, 5028-5048.

(17) Anthony, J. E. Angew. Chem. Int. Ed. 2008, 47, 452-483.

(18) Xiao, C.; Kan, X.; Liu, C., et al. J. Mater. Chem. C Mater. Opt. Electron. Devices 2017, 5, 2702-2707.

(19) Murtaza, G.; Ahmad, I.; Chen, H.; Wu, J. Synth. Met. 2014, 194, $146-152$.

(20) Yu, X.; Zhou, N.; Han, S., et al. J. Mater. Chem. C Mater. Opt. Electron. Devices 2013, 1, 6532.

(21) Lee, J. H.; Seo, Y.; Park, Y. D., et al. Sci. Rep. 2019, 9, 21.

(22) Walker, B. J.; Musser, A. J.; Beljonne, D.; Friend, R. H. Nat. Chem. 2013, 5, 1019-1024.

(23) Herz, J.; Buckup, T.; Paulus, F.; Engelhart, J. U.; Bunz, U. H. F.; Motzkus, M. J. Phys. Chem. A 2015, 119, 6602-6610.

(24) Purushothaman, B.; Bruzek, M.; Parkin, S. R.; Miller, A-F.; Anthony, J. E. Angew. Chem. Int. Ed. 2011, 50, 7013-7017.

(25) Payne, M. M.; Parkin, S. R.; Anthony, J. E. J. Am. Chem. Soc. 2005, 127, 8028-8029.

(26) Bunz, U. H. F. Pure Appl. Chem. 2010, 82, 953-968.

(27) Bunz, U. H. F.; Engelhart, J. U.; Lindner, B. D.; Schaffroth, M. Angew. Chem. Int. Ed. 2013, 52, 3810-3821.

(28) Engelhart, J. U.; Tverskoy, O.; Bunz, U. H. F. J Am. Chem. Soc. 2014 136, 15166-15169.

(29) Bunz, U. H. F. Acc. Chem. Res. 2015, 48, 1676-1686.

(30) Fogel, Y.; Kastler, M.; Wang, Z.; Andrienko, D.; Bodwell, G. J.; Müllen, K. J. Am. Chem. Soc. 2007, 129, 11743-11749.

(31) Kohl, B.; Rominger, F.; Mastalerz, M. A. Angew. Chem. Int. Ed. 2015, 54, 6051-6056.

(32) Li, J.; Zhang, Q. ACS Appl. Mater. Interfaces 2015, 7, 28049-28062

(33) Zuzak, R.; Dorel, R.; Kolmer, M.; Szymonski, M.; Godlewski, S.; Echavarren, A. M. Angew. Chem. Int. Ed. 2018, 57, 10500-10505.

(34) Krüger, J.; García, F.; Eisenhut, F., et al. Angew. Chem. Int. Ed. 2017, $56,11945-11948$

(35) Einholz, R.; Fang, T.; Berger, R., et al. J. Am. Chem. Soc. 2017, 139, 4435-4442

(36) Mondal, R.; Shah, B. K.; Neckers, D. C. J. Am. Chem. Soc. 2006, 128, 9612-9613.

(37) Clar, E. Polycyclic Hydrocarbons: Volume 1. Springer: Berlin, Heidelberg, 1964.

(38) Biermann, D.; Schmidt, W.J. Am. Chem. Soc. 1980, 102, 3173-3181.

(39) Tang, M.; Yu, Q.; Wang, Z., et al. Org. Lett. 2018, 20, 7620-7623.

(40) Clar, E.; Mullen, A. Tetrahedron 1968, 24, 6719-6724.
(41) Gutman, I.; Petrović, V. Monatsh. Chem. 1995, 126, 1179-1185.

(42) Wright, P. T. Synthesis 1997, 1997, 1007-1009.

(43) Liu, Z.; Zhang, X.; Larock, R. C. J. Am. Chem. Soc. 2005, 127, 15716-15717.

(44) Eistert, B.; Fink, H.; Werner, H-K. Justus. Liebigs. Ann. Chem. 1962, 657, 131-141.

(45) Ha, S. D.; Kaafarani, B. R.; Barlow, S.; Marder, S. R.; Kahn, A.J. Phys. Chem. C 2007, 111, 10493-10497.

(46) Selzer, F.; Falkenberg, C.; Hamburger, M., et al.J. Appl. Phys. 2014, 115,54515

(47) Cortizo-Lacalle, D.; Pertegás, A.; Martínez-Sarti, L.; MelleFranco, M.; Bolink, H. J.; Mateo-Alonso, A. J. Mater. Chem. C Mater. Opt. Electron. Devices 2015, 3, 9170-9174.

(48) Lynett, P. T.; Maly, K. E. Org. Lett. 2009, 11, 3726-3729.

(49) Schuler, B.; Collazos, S.; Gross, L., et al. Angew. Chem. Int. Ed. 2014 53, 9004-9006.

(50) Alonso, J. M.; Díaz-Álvarez, A. E.; Criado, A.; Pérez, D.; Peña, D.; Guitián, E. Angew. Chem. Int. Ed. 2012, 51, 173-177.

(51) Rüdiger, E. C.; Rominger, F.; Steuer, L.; Bunz, U. H. F. J. Org. Chem. 2016, 81, 193-196.

(52) Rüdiger, E. C.; Porz, M.; Schaffroth, M.; Rominger, F.; Bunz, U. H. F. Chem. Eur. J. 2014, 20, 12725-12728.

(53) Platt, A. D.; Day, J.; Subramanian, S.; Anthony, J. E.; Ostroverkhova, O. J. Phys. Chem. C. 2009, 113, 14006-14014.

(54) Odom, S. A.; Parkin, S. R.; Anthony, J. E. Org. Lett. 2003, 5, $4245-4248$

(55) Mora-Fuentes, J. P.; Riaño, A.; Cortizo-Lacalle, D.; Saeki, A.; Melle-Franco, M.; Mateo-Alonso, A. Angew. Chem. Int. Ed. 2019 $58,552-556$.

(56) Zhou, Z-h.; Yamamoto, T. J. Organomet. Chem. 1991, 414, 119-127.

(57) Rüdiger, E. C.; Koser, S.; Rominger, F.; Freudenberg, J.; Bunz, U. H. F. Chem. Eur. J. 2018, 24, 9919-9927.

(58) Yuan, C.; Saito, S.; Camacho, C.; Kowalczyk, T.; Irle, S.; Yamaguchi, S. Chem. Eur. J. 2014, 20, 2193-2200.

(59) Hu, B-L.; Zhang, K.; An, C.; Schollmeyer, D.; Pisula, W.; Baumgarten, M. Angew. Chem. Int. Ed. 2018, 57, 12375-12379.

(60) Cortizo-Lacalle, D.; Mora-Fuentes, J. P.; Strutyński, K.; Saeki, A.; Melle-Franco, M.; Mateo-Alonso, A. Angew. Chem. Int. Ed. 2018 57, 703-708.

(61) Zhang, G.; Rominger, F.; Zschieschang, U.; Klauk, H.; Mastalerz, M. Chem. Eur. J. 2016, 22, 14840-14845.

(62) Yang, W.; Monteiro, J. H. S. K; de Bettencourt-Dias, A.; Catalano, V. J.; Chalifoux, W. A. Chem. Eur. J. 2019, 25, 1441-1445.

(63) Rüdiger, E. C.; Müller, M.; Koser, S.; Rominger, F.; Freudenberg, J.; Bunz, U. H. F. Chem. Eur. J. 2018, 24, 1036-1040.

(64) Müller, M.; Rüdiger, E. C.; Koser, S., et al. Chem. Eur. J. 2018, 24 8087-8091.

(65) Gaussian 09, Revision D, M. J. Frisch, G. W. Trucks, H. B. Schlegel, G. E. Scuseria, M. A. Robb,J.R. Cheeseman, G.Scalmani, V. Barone, G. A. Petersson, H. Nakatsuji, X. Li, M. Caricato, A. Marenich, J. Bloino, B. G.Janesko, R. Gomperts, B. Mennucci, H. P. Hratchian,J.V. Ortiz, A. F Izmaylov, J. L. Sonnenberg, D. Williams-Young, F. Ding, F. Lipparini, F. Egidi, J. Goings, B. Peng, A. Petrone, T. Henderson, D. Ranasinghe, V. G. Zakrzewski, J. Gao, N. Rega, G. Zheng, W. Liang, M. Hada, M. Ehara, K. Toyota, R. Fukuda, J. Hasegawa, M. Ishida, T. Nakajima, Y. Honda, O. Kitao, H. Nakai, T. Vreven, K. Throssell, J. A. Montgomery, Jr., J. E. Peralta, F. Ogliaro, M. Bearpark, J. J. Heyd, E. Brothers, K. N. Kudin, V. N. Staroverov, T. Keith, R. Kobayashi, J. Normand, K. Raghavachari, A. Rendell, J. C. Burant, S. S. Iyengar, J. Tomasi, M. Cossi, J. M. Millam, M. Klene, C. Adamo, R. Cammi, J. W. 
Organic Materials

Ochterski, R. L. Martin, K. Morokuma, O. Farkas, J. B. Foresman, and D. J. Fox, Gaussian, Inc., Wallingford CT, 2016.

(66) Crystallographic data from the Cambridge Structural Database (pentacene: CCDC 114447, TIPS-Pen CCDC 172476).

(67) Crystallographic data from the Cambridge Structural Database (P3: CCDC 1004995, T3 CCDC 100499).
(68) Crystallographic data from the Cambridge Structural Database (PB2: CCDC 1560190, PV2 1560191).

(69) Crystallographic data from the Cambridge Structural Database (CCDC 1826259).

(70) Crystallographic data from the Cambridge Structural Database (CCDC 1908230). 